\title{
Risk-benefit considerations in the treatment of relapsing-remitting multiple sclerosis
}

This article was published in the following Dove Press journal:

Neuropsychiatric Disease and Treatment

22 June 2013

Number of times this article has been viewed

\author{
Alessandra Lugaresi' \\ Maria di loia' \\ Daniela Travaglini' \\ Erika Pietrolongo' \\ Eugenio Pucci ${ }^{2}$ \\ Marco Onofrj' \\ 'Department of Neuroscience and \\ Imaging, University "G d'Annunzio", \\ Chieti, ${ }^{2}$ Operative Unit Neurologia \\ ASUR Marche Area Vasta 3, Macerata, \\ Italy
}

\begin{abstract}
Multiple sclerosis (MS) is a chronic demyelinating disease of the central nervous system and mainly affects young adults. Its natural history has changed in recent years with the advent of disease-modifying drugs, which have been available since the early 1990s. The increasing number of first-line and second-line treatment options, together with the variable course of the disease and patient lifestyles and expectations, makes the therapeutic decision a real challenge. The aim of this review is to give a comprehensive overview of the main present and some future drugs for relapsing-remitting MS, including risk-benefit considerations, to enable readers to draw their own conclusions regarding the risk-benefit assessment of personalized treatment strategies, taking into account not only treatment-related but also disease-related risks. We performed a Medline literature search to identify studies on the treatment of MS with risk stratification and risk-benefit considerations. We focused our attention on studies of disease-modifying, immunomodulating, and immunosuppressive drugs, including monoclonal antibodies. Here we offer personal considerations, stemming from long-term experience in the treatment of MS and thorough discussions with other neurologists closely involved in the care of patients with the disease. MS specialists need to know not only the specific risks and benefits of single drugs, but also about drug interactions, either in simultaneous or serial combination therapy, and patient comorbidities, preferences, and fears. This has to be put into perspective, considering also the risks of untreated disease in patients with different clinical and radiological characteristics. There is no single best treatment strategy, but therapy has to be tailored to the patient. This is a time-consuming task, rich in complexity, and influenced by the attitude towards risk on the parts of both the patient and the clinical team. The broader the MS drug market becomes, the harder it will be for the clinician to help the patient decide which therapeutic strategy to opt for.
\end{abstract}

Keywords: safety, efficacy, effectiveness, doctor-patient relationship, shared decisionmaking

\section{Introduction}

Multiple sclerosis (MS) is a chronic demyelinating disease of the central nervous system and is characterized by inflammation and axonal degeneration. It is the most common cause of neurologic disability in young adults in the Western world, affecting mostly people aged 20-40 years of age, with a female to male ratio which has increased in recent decades from $2: 1$ to $3: 1{ }^{1}$

In most cases, MS has a relapsing-remitting course. ${ }^{2}$ After about 10 years, approximately 50\% of patients with relapsing-remitting MS gradually develop permanent disability, entering the phase known as secondary progressive MS. ${ }^{3}$ After a median of 15-28 years from disease onset, an assistive walking device is needed.,
Correspondence: Alessandra Lugares MS Center, Ospedale Clinicizzato

"SS Annunziata", Via dei Vestini 13, 66100 Chieti, Italy

Tel +3908 71358532

Fax +390871358523

Email lugaresi@unich.it 
Benign MS, defined as no or minimal disability at 10 or 20 years, is a controversial definition because, 10 years on, only $25 \%$ of those initially classified as benign still have mild disability and as many as 50\% have significant neuropsychologic deficits. ${ }^{5,6}$ Cognitive impairment, ignored in the past, contributes to disability in MS and has prevalence rates between $43 \%$ and $70 \% .^{7} \mathrm{MS}$ often has a very negative impact on quality of life. ${ }^{8}$ Quality of life has also recently become an endpoint in clinical trials.

Although the progressive phase appears to be independent of previous relapses but age-dependent, meaning that a younger age at disease onset correlates with a younger age in reaching milestones of disability, relapses also represent meaningful outcomes. ${ }^{9}$ In relapsing-remitting MS, progression of disability occurs in the context of relapses. ${ }^{10}$ Even when complete remission occurs, relapses may cause a level of temporary disability that disrupts family, social, and working life, undermining patients' confidence, and restricting their ability to participate in society.

\section{Treatment for relapsing-remitting MS: overview}

In the 1990s, the first disease-modifying drugs, in particular interferon beta (IFN $\beta$ ) and glatiramer acetate, were approved for treatment of MS. ${ }^{11}$ In recent years, both IFN $\beta$ and glatiramer acetate have been found to be effective in patients with clinically isolated syndrome in terms of prolonged time to conversion to clinically definite MS, rendering early diagnosis meaningful. ${ }^{12}$ The advent of disease-modifying drugs has shifted the focus of management of relapsing-remitting MS from treatment of acute exacerbations to prevention of new disease activity possibly affecting future disability. In recent years and months, the scenario of therapies for MS has widened with the advent of new drugs. Approved drugs for relapsing-remitting MS, that in spring 2013 include subcutaneous and intramuscular IFN $\beta$ formulations, glatiramer acetate, natalizumab, mitoxantrone, fingolimod and, in some countries, new oral drugs (teriflunomide and dimethylfumarate), are reviewed here. We appraise nonselective immunosuppressive agents (cyclophosphamide, methotrexate, azathioprine) which, although not approved for treatment of MS in most countries, are frequently used in clinical practice.

We also anticipate the benefits and risks of drugs that are reaching the end of the experimental phase and are going to be commercially available in the future. Overall, although disease-modifying drugs are efficacious in decreasing disease activity and progression in the short term and medium term, data on long-term effectiveness are still scarce.
Presently, reduction of relapse rate and radiological activity (intended as new or enlarging T2 lesions and gadolinium-enhancing lesions) are the main parameters measured in clinical trials. Onset of progression and degree of disability after 5-10 years or more are further parameters which are useful in evaluation of the long-term efficacy of these drugs, although it is not always possible to have an adequate comparator group of untreated patients for ethical reasons. For this purpose, real-life observational studies using propensity scores or other appropriate statistical methods are useful, giving measures of effectiveness, rather than efficacy, and overcoming the issue of heterogeneity of placebo groups across pivotal and extension studies. ${ }^{13}$

Because new and possibly more effective therapies for MS are emerging, it is reasonable to expect that outcome measures, such as sustained improvement in physical disability, measured by the Expanded Disability Status Scale, will be used in clinical MS trials. ${ }^{14}$

\section{Literature search}

Given that the scope of this review is to offer considerations about relapsing-remitting MS, a systematic bibliographic search was not deemed necessary. However, a PubMed search up to January 2013 was conducted using the following medical subject headings: "risk assessment", "drug therapy", "multiple sclerosis", "risk", "benefit", "considerations", and individual drug names. Hand searching of references from review articles and proceedings of the main conferences held in the last five years was carried out to locate other articles of possible interest. The relevance of papers was first assessed by reading the titles and abstracts. Each author critically reviewed the literature. Next, AL assessed key ideas and drafts from the single authors, compared them, resolved conflicts, and was responsible for the final version. For brevity, we focused our attention on disease-specific drugs for relapsing-remitting MS and avoided an evaluation of symptomatic treatments. Our appraisal does not take into concern the economic perspective including the issue of cost-effectiveness analysis.

\section{Drugs already on the market Beta interferons}

IFN $\beta$-1b (Betaseron $^{\circledR}$, Bayer HealthCare, Leverkusen, Germany; Extavia $^{\circledR}$, Novartis, Cambridge, MA, USA) was the first drug approved by the Food and Drug Administration (FDA) in 1993, on the basis of the results of pivotal, randomized, controlled clinical trials. ${ }^{15,16}$ Other IFN $\beta$ formulations are also approved, ie, IFN $\beta$-1a (Avonex ${ }^{\circledR}$, Biogen 
Idec, Cambridge, MA, USA) and IFN $\beta$-1a (Rebif ${ }^{\circledR}$, Merck Serono, Billerica, MA, USA). ${ }^{17,18}$ IFN $\beta$ is involved in the immune response, with antiviral and antiproliferative effects. Antiviral properties contribute to the favorable safety profile of IFN $\beta$, whereas its antiproliferative effects can interfere with wound healing and have mild but measurable effects in exposed pregnancies. ${ }^{19} \mathrm{~A}$ favorable effect of higher frequency and higher doses of IFN $\beta$ on both clinical and magnetic resonance imaging (MRI) outcomes has been observed..$^{20-22}$

The CHAMPS, ${ }^{23} \mathrm{ETOMS}^{24}{ }^{24} \mathrm{BENEFIT}^{25}$ and REFLEX ${ }^{26}$ studies have shown a beneficial effect of IFN $\beta$ in patients with clinically isolated syndromes in terms of prolonged time to conversion to clinically definite MS. Based on the results of these randomized, controlled clinical trials, both the FDA and European Medicines Agency approved the use of IFN $\beta$ in individuals who have experienced a first neurological episode and have clinical and MRI features consistent with MS. However, no differences were found in disability outcomes measured as Expanded Disability Status Scale and Multiple Sclerosis Functional Composite scores nor in MRI outcomes, indicating that although treatment delays conversion to clinically definite MS, a delay in treatment does not necessarily imply greater disability progression. ${ }^{27,28}$ This is still controversial, given that some observational, but methodologically sound, studies showed that early initiation of treatment with IFN $\beta$ is associated with a reduction in progression of disability. ${ }^{29-31}$

Randomized, controlled clinical trials including both patients with relapsing-remitting MS and those with secondary progressive MS showed that there is a therapeutic window within which initiating treatment can positively affect development of disability. All trials also showed a favorable long-term safety and tolerability profile. ${ }^{32}$ The 21-year long-term follow-up of patients who participated in the randomized, controlled clinical trial of IFN $\beta-1 b$ showed that early treatment is associated with better survival and all-cause mortality in patients with relapsing-remitting MS compared with placebo. ${ }^{33}$

The most common side effects of IFN $\beta$ are flu-like symptoms (fever, myalgia, chills, headache), occurring in about $75 \%$ of patients within 1-6 hours of injection, and the local site reactions (pain, erythema, pruritus, and less commonly necrosis and lipoatrophy) occurring with the subcutaneous formulations. These adverse events impact adherence. Use of symptomatic agents and autoinjection devices improves adherence. ${ }^{34,35}$ Other adverse events potentially affecting adherence are worsening of weakness and spasticity.
A review of the literature on psychiatric side effects of IFN $\beta$ in MS did not show an association between IFN $\beta$ and depression or suicide. ${ }^{36,37}$ An observational study found that depression remained largely stable over three years of IFN $\beta$ treatment. ${ }^{38}$

Periodic hematochemical analyses are recommended, because lymphopenia, elevation of aminotransferases, and thyroid dysfunction are common, especially with the higherdose regimens, although are usually subclinical..$^{39,40}$

Neutralizing antibodies can form during treatment with IFN $\beta$, affecting biological activity and, although this is still controversial, clinical and especially radiological efficacy. To help the decision on whether to modify treatment after a relapse or reactivation on MRI, it seems wise to test patients for neutralizing antibodies. ${ }^{41}$

Among the different IFN $\beta$ formulations, neutralizing antibodies develop more frequently with subcutaneous IFN $\beta-1 b$ due to its higher immunogenicity, and less frequently, with once-weekly intramuscular IFN $\beta-1 \mathrm{a}{ }^{42}$ This might impact the choice between the different IFN $\beta$ formulations. In recent analyses, no association was found between IFN $\beta$ and an increased risk of any kind of cancer, ${ }^{43}$ contrary to earlier publications. $^{44}$

\section{Glatiramer acetate}

Based on two trials showing efficacy in relapsing-remitting MS, ${ }^{45,46}$ glatiramer acetate (Copaxone ${ }^{\circledR}$, Teva Pharmaceutical Industries Ltd, Petah Tikva, Israel) was approved by the FDA in 1996 as first-line treatment for relapsing-remitting MS. ${ }^{47}$ The efficacy of glatiramer acetate in relapsing-remitting MS and clinically isolated syndrome was subsequently confirmed. ${ }^{48,49}$ In a test of comparative efficacy, glatiramer acetate was superior to IFN $\beta$-1a $30 \mu \mathrm{g}$ intramuscularly once weekly in reducing the risk of exacerbation. ${ }^{50}$ The REGARD (glatiramer acetate versus subcutaneous IFN $\beta$-1a) and Beyond and Become (IFN $\beta-1 b$ ) studies failed to show the superiority of high-dose IFN $\beta$ compared with glatiramer acetate on primary endpoints, although glatiramer acetate appeared to be less efficient on some MRI parameters. ${ }^{51-53}$ Therefore, it is common practice to consider glatiramer acetate as an alternative option to high-dose IFN $\beta .{ }^{54}$ Extension studies reporting results up to 15 years of treatment show that the group treated with glatiramer acetate has maintained a reduced relapse rate, a slowing in progression, and good tolerability, without evidence of new safety signals. ${ }^{55}$

Among therapy-related adverse events, the most common is injection site reaction (occurring in $56 \%-78 \%$ of cases and manifesting as hematoma, skin necrosis, erythema, pain, 
pruritus, and subcutaneous lipoatrophy). ${ }^{56}$ The main systemic adverse event described is the so-called "systemic reaction", starting immediately after the injection, usually lasting about 30 seconds, and characterized by hot flushing, chest tightness, dyspnea, palpitations, and anxiety. This reaction has an average incidence of 5\%. Lymph node swelling has been reported in the first weeks of treatment. In an observational study, 12 months after starting treatment with glatiramer acetate, there were no statistically significant changes in Beck Depression Inventory-Short Form scores. ${ }^{57}$ Anaphylactic reactions have occurred rarely. ${ }^{58,59}$

A recently published review addressing the issue of the risk-benefit ratio for glatiramer acetate concluded that the benefits outweigh the risks. ${ }^{47}$ Glatiramer acetate is by far the safest drug on the market. However, when complicated by lipoatrophy and subcutaneous nodules, the local reaction not only makes the injection painful, but also hinders absorption, leading to loss of efficacy. Therefore, in the case of glatiramer acetate, the risk is related not to the adverse event profile, but to loss of efficacy and poor adherence.

\section{Mitoxantrone}

Mitoxantrone was approved for progressive relapsing and secondary progressive MS in 2000. After the conclusion of the European Mitoxantrone in Multiple Sclerosis Group Phase III study in 2002, the FDA extended approval to aggressive relapsing-remitting MS. Mitoxantrone is administered intravenously at a dose of $8 \mathrm{mg} / \mathrm{m}^{2}$ body surface monthly for six months according to the French protocol, or at a dose of $12 \mathrm{mg} / \mathrm{m}^{2}$ every three months for two years, as in the Mitoxantrone in Multiple Sclerosis Group study, but the regimens used in clinical practice vary. In our opinion, $8 \mathrm{mg} / \mathrm{m}^{2}$ bimonthly infusions have a better risk-benefit profile. The maximum recommended cumulative dose ranges from $120 \mathrm{mg} / \mathrm{m}^{2}$ in MS in Italy to $140 \mathrm{mg} / \mathrm{m}^{2}$ in cancer. ${ }^{60,61}$ Mitoxantrone has long-term efficacy after discontinuation, allowing for induction therapy in aggressive cases. ${ }^{60}$

The most frequent adverse events are nausea/vomiting, alopecia, infection, thrombocytopenia, anemia, increased liver enzymes, and amenorrhea/infertility. ${ }^{61}$ Use of mitoxantrone is limited by cardiotoxicity and the risk of therapyrelated acute myeloid leukemia (TRAL). The overall estimated risk of decreased systolic function is $12 \%$, which is sometimes asymptomatic. The risk of congestive heart failure is $0.4 \%$. Cardiotoxicity can be idiosyncratic, with post-marketing reports at a cumulative dose $<100 \mathrm{mg} / \mathrm{m}^{2}$. To monitor cardiac function, evaluation of left ventricular ejection fraction is recommended after each infusion with three-monthly infusions, but it is unclear whether closer monitoring should be performed with different regimens. Recent reports have documented a risk for TRAL between $2 \%$ and $3 \%$ after a mean follow-up of five years, ${ }^{62}$ and $0.93 \%$ after a mean follow-up of four years, with a $3 \%$ increase for every one unit increase in cumulative dose. ${ }^{63}$ Rare cases of acute lymphoblastic leukemia and chronic myeloid leukemia have also been reported. Combining all reports, TRAL occurs in about $0.8 \%$ of mitoxantrone-treated patients, especially after a cumulative dose $>70 \mathrm{mg} / \mathrm{m}^{2}{ }^{63}$ On the basis of current knowledge, a cumulative dose up to $60 \mathrm{mg} / \mathrm{m}^{2}$ can be used without a relevant increase in the risk of TRAL. ${ }^{60,63}$ Therefore, it is recommended to monitor patients with MS on mitoxantrone for TRAL and cardiotoxicity also in the five years after discontinuation of mitoxantrone therapy, even if guidelines on timing of such monitoring are lacking.

\section{Natalizumab}

Natalizumab (Tysabri ${ }^{\circledR}$, Biogen Idec) is the first monoclonal antibody approved as monotherapy for the treatment of relapsing-remitting MS. Initially approved by the FDA in 2004, natalizumab was taken off the market in 2005 after three fatal cases of progressive multifocal leukoencephalopathy (PML) caused by reactivation of latent JC virus infection. After a safety review in 2006, natalizumab was again on the market, but under safety programs to mitigate the risk of PML.

The pivotal trials (AFFIRM and SENTINEL) ${ }^{64,65}$ showed that natalizumab reduces exacerbation, progression, and MRI burden, and has a positive effect on quality of life. Efficacy of natalizumab was found in a Cochrane meta-analysis. ${ }^{66} \mathrm{~A}$ post hoc analysis of the AFFIRM study showed that natalizumab can favor disease remission (eg, no clinical or radiological disease activity). ${ }^{67}$ Some studies showed that natalizumab is effective in reducing the risk of cognitive deterioration and fatigue. ${ }^{68}$ The regulatory agencies recommend use of natalizumab for patients with relapsing-remitting MS with high disease activity despite a first-line therapy or with rapidly evolving severe relapsing-remitting MS. ${ }^{69}$

Focusing attention on the main safety concern about natalizumab, it has to be underscored that primary JC virus infection is common but asymptomatic in immunocompetent patients. The causes of PML in natalizumab-treated patients have not yet been fully elucidated. ${ }^{70}$ PML in the setting of natalizumab treatment compared with PML in other settings, in particular in patients with acquired immunodeficiency syndrome, shows differences. In particular, in natalizumab-associated PML, lesions often show MRI 
contrast enhancement at presentation and, after plasma exchange, inflammation generally increases due to immune reconstitution syndrome. ${ }^{71}$ Although PML remains a very severe and worrisome complication of natalizumab, $80 \%$ of patients survive with moderate to severe disability, There are three currently recognized risk factors, ie, a positive anti-JC virus antibody serostatus, which can be evaluated with the Stratify $\mathrm{JCV}^{\circledR}$ test offered by Biogen Idec, prior or current immunosuppressant therapy, and duration of natalizumab therapy (especially if longer than two years). Patients with a negative Stratify JCV test have the lowest risk (estimated as 0.09 cases or fewer per 1000 patients). Patients positive for all three risk factors have an estimated risk of 10.6 per 1000 patients (Biogen Idec, data on file, March 2013). The use of an algorithm including the Stratify JCV test, prior immunosuppressant use, and treatment duration is deemed helpful in assessing the risk of PML when sharing the decision to stop natalizumab treatment with the patient. Individual severity of MS, prior use and failure of disease-modifying drugs, and the efficacy and safety of alternative therapies have to be taken into consideration and discussed with the patient, to share the decisions on initiation and duration of treatment. ${ }^{72}$ In seronegative patients, it is recommended to repeat the Stratify JCV test every six months during treatment with natalizumab, to evaluate seroconversion.

We would also recommend to perform the test, along with MRI scanning, in case of clinical events. In a longitudinal analysis, around $10 \%$ of patients converted from an anti-JC virus antibody-negative to seropositive status over around eight months. ${ }^{73}$ This might be partly the effect of a more sensitive technique used to detect anti-JC virus antibodies and can generate anxiety in seroconverted patients. It has been suggested that, after 24 months, MRI should be repeated every six months for early detection of areas suggestive of PML in seropositive patients who do not wish to discontinue treatment. This would enhance early diagnosis, reducing the risk of severe disability and death. Polymerase chain reaction for detection of JC virus DNA in the cerebrospinal fluid has to be performed in suspected cases of PML. The use of plasma exchange to remove natalizumab is controversial, because it enhances MS reactivation and immune reconstitution syndrome. Although clear guidelines are missing, it seems safer to treat immune reconstitution syndrome with steroids only if PML is confirmed, because preventive use might cause immunosuppression and increase the risk of PML, rather than preventing MS reactivation, after discontinuation of natalizumab. ${ }^{74}$
Several reports have documented reactivation of MS after discontinuation of natalizumab. The majority of patients showed MRI and clinical activity comparable with that prior to disease-modifying drug treatment within 2-6 months after stopping natalizumab, independently of initiation of other treatments (including fingolimod). ${ }^{75-80}$ These issues should be clearly explained to patients before starting treatment.

A pregnancy exposure registry has been established for natalizumab. Preliminary data have not shown severe adverse effects on the outcomes of pregnancy. ${ }^{69,81}$ The preliminary findings of the registry, although apparently reassuring, are not sufficient to suggest women should not discontinue treatment if planning a pregnancy, but helps in deciding whether to interrupt pregnancy in exposed women.

In conclusion, natalizumab, although associated with a variable risk of PML, is a very effective treatment for relapsing-remitting MS and is well tolerated. A benefitrisk evaluation is mandatory in every single patient. The decision to start or continue natalizumab or to switch to another available drug must take into account the clinical and radiological characteristics before any treatment, disease-modifying drug treatment, disease duration, and accumulation of disability. ${ }^{82}$ After an open and transparent presentation of the risks and benefits of treatment versus discontinuation, neurologists should respect the opinion of the patient, which is heavily influenced by fear (of physical disability and cognitive impairment more than death) and past experience of the disease (markedly aggressive, unresponsive to conventional treatment). In general, patients accept the risk of natalizumab-associated PML if progression of MS is their primary concern and if they have experienced highly active disease despite a first-line therapy. ${ }^{83}$ In the decision-making process, in the absence of clearcut guidelines, the attitute towards risk management both of therapy and untreated disease of the individual neurologist play an important role in the process of informing the patient and the decision is the product of an exclusive doctor-patient relationship. ${ }^{84} \mathrm{~A}$ study has demonstrated that, compared with their neurologists, natalizumab-treated patients perceive MS to be more malignant and natalizumab to be more effective, and that there are no significant differences between patients and neurologists regarding perception of PML risk, but patients generally accept higher risks than physicians. ${ }^{85}$

Although a quantitative risk-benefit analysis of natalizumab in 2008 showed that the benefits of long-term treatment with natalizumab far exceeded the risk of developing PML, we should now reconsider that statement in different 
MS cohorts. ${ }^{86}$ Although some Authors consider the risk of natalizumab-related PML, death, or severe disability unacceptable and prefer the use of safer drugs, ${ }^{87}$ the majority of clinicians argue that this risk can be minimized using risk stratification combined with high clinical and MRI vigilance in each patient. ${ }^{88,89}$

\section{Fingolimod}

Fingolimod (FTY720, Gilenya ${ }^{\circledR}$, Novartis) was approved by the FDA in 2010 as first-line therapy for relapsing-remitting MS. It has been authorized in the European Union since March 2011 as second-line treatment. The different positioning might reflect the different health systems, with attention focused on efficacy in the US and safety in the European Union.

The approved dose of $0.5 \mathrm{mg}$ appears to be efficacious but safer, according to the results of two large published, randomized, double-blind, controlled Phase III trials (FREEDOMS and TRANSFORMS). ${ }^{90,91}$ The annualized relapse rate (primary endpoint) was significantly lower and disability progression delayed in patients treated with fingolimod compared with placebo in FREEDOMS I. Similar results were reported for FREEDOMS II by Calabresi et al. ${ }^{92,93}$ Also, in TRANSFORMS (one year duration of blinded phase), the annualized relapse rate (primary endpoint) was significantly lower in patients treated with fingolimod compared with IFN $\beta$-1a, but there were no significant differences in time to progression of disability at three months. The number of new and newly enlarging T2 lesions was significantly lower in patients treated with fingolimod than in patients who received IFN $\beta-1 \mathrm{a} .{ }^{91}$ After these trials, fingolimod $0.5 \mathrm{mg}$ seems to provide the best risk-benefit ratio and is the approved dose.

Regarding safety, adverse events reported in these trials were bradycardia (after the first dose), transient second degree Wenckebach atrioventricular block, decreased pulmonary function (forced expiratory volume in one second), macular edema, liver toxicity, and mild hypertension. In FREEDOMS II, the incidence of symptomatic bradycardia was $0.8 \%$ in the fingolimod group versus $0.3 \%$ in the placebo group. ${ }^{93}$ In the extension phase of FREEDOMS, with data up to four years, no new or unexpected adverse events have come to light. ${ }^{94,95}$

After the sudden death of a patient in the US within 24 hours of the first dose of fingolimod and 11 cases of probable cardiovascular death in Europe, new recommendations have been issued for cardiac monitoring after the first dose of fingolimod and in the event of restarting after discontinuation. Concurrent medication that could cause bradycardia, prolong the QT interval, or cause arrhythmias has to be used with caution. ${ }^{96-98}$

During TRANSFORMS, two fatal infections occurred in the group receiving the $1.25 \mathrm{mg}$ dose, ie, disseminated primary varicella zoster and herpes simplex encephalitis. ${ }^{91}$ This led to the recommendation to assess varicella zoster serostatus before initiation of fingolimod, and vaccination in seronegative cases. This might not prevent mortality, because serostatus might change and concomitant steroid use might decrease immune surveillance also in immunized subjects.

Opportunistic infections and malignancies (seven cases of skin cancer, lymphoma) have also been reported, but the actual incidence has still to be determined (Novartis, data on file). In FREEDOMS II, the incidence of herpes infections, hypertension, and basal cell carcinoma were higher, but pooled analysis from three pivotal Phase III trials and a Phase II study did not confirm these findings. ${ }^{93}$

Severe relapses and tumefactive lesions have been described when fingolimod treatment was started 3-4 months after discontinuation of natalizumab. ${ }^{99}$ However, tumefactive lesions during fingolimod treatment were reported also in cases not previously treated with natalizumab, as reviewed by Hardy and Chataway. ${ }^{100}$ In April 2012, Novartis announced that a patient with MS treated with fingolimod and previously treated with natalizumab had been diagnosed with PML. ${ }^{101}$ Therefore, caution must be exercised about switching from natalizumab to fingolimod at the time of immune reconstitution. Recently, some reports have been published highlighting the still unknown potential rebound effects of discontinuation of fingolimod. ${ }^{102,103}$

A recent pooled analysis of safety data from Phase II, Phase III, and extension studies for fingolimod (all doses, $\mathrm{n}=3553$; 9070 patient years, with 1510 patients treated for more than three years and some seven years) show a good safety profile consistent with previous results. ${ }^{104}$ Similar results have been reported in clinical practice. ${ }^{105}$

The observational FIRST study, which evaluated safety in a setting similar to that of clinical practice, where comorbidities did not constitute an exclusion criterion, enrolled approximately 2400 patients with relapsing-remitting MS and underlying cardiac conditions (Mobitz type I seconddegree atrioventricular block, symptomatic bradycardia, a positive tilt test, concomitant use of beta blockers). Cardiac events (overall considered to be of a benign nature) related to initiation of fingolimod were recorded in less than $5 \%$ of patients, with a slightly higher frequency in the cardiac risk subgroup. ${ }^{106-108}$ A German national safety register 
(1850 patients) provided evidence of symptomatic bradycardia at initiation in only $0.6 \%$ of patients. ${ }^{109}$ The FIRST trial also demonstrated that macular edema is more frequent in patients with diabetes and in those aged $>55$ years. ${ }^{107}$ The drug is potentially teratogenic, so is contraindicated in pregnancy and during breastfeeding.

With more than 49,000 patients exposed to fingolimod as of November 2012 and 135 patients who had been treated and followed up for $\geq 7$ years at the time of European Medicines Agency (EMA) approval, fingolimod can be used with confidence as a second-line treatment in an appropriate setting and following the safety recommendations. ${ }^{110}$ Further ongoing observational post-marketing studies will help to clarify the relative long-term safety, tolerability, and efficacy of fingolimod with respect to other disease-modifying drugs.

\section{Teriflunomide}

Teriflunomide (Aubagio ${ }^{\circledR}$, Genzyme, Haverhill, UK) is an immunomodulatory and anti-inflammatory drug at the doses approved for MS. ${ }^{111}$ It is the active metabolite of leflunomide, a drug prescribed in rheumatoid arthritis and psoriatic arthritis. Teriflunomide ( $7 \mathrm{mg}$ or $14 \mathrm{mg}$ orally once daily) has been approved by the FDA as a first-line treatment for patients with relapsing-remitting MS, based on efficacy and safety data derived from core Phase II and Phase III studies (TEMSO, TOWER, TENERE) ${ }^{112-115}$ and the respective extension studies. ${ }^{116,117}$ In the pivotal studies, the most common adverse events were nasopharyngitis, headache, diarrhea, fatigue, neutropenia, elevated alanine aminotransferase, nausea, hair thinning or decreased hair density, flu-like symptoms, back pain, urinary tract infections, and pain in the limbs.

The TENERE study demonstrated that teriflunomide was not inferior to subcutaneous IFN $\beta$-1a with regard to rates of treatment failure. ${ }^{115}$ In the TERACLES study, teriflunomide as add-on therapy to IFN $\beta$ was safe and decreased MRI activity compared with IFN $\beta$ alone, indicating possible synergic efficacy. ${ }^{118}$ Enhanced liver toxicity might be an issue, considering data from the leflunomide studies. ${ }^{119}$

The as yet unpublished results of the TOPIC study show that teriflunomide can prevent or delay conversion to clinically definite MS, ${ }^{120}$ making teriflunomide the first oral treatment with efficacy data in patients with clinically isolated syndromes. Teriflunomide does not appear to interfere with seasonal influenza vaccination (TERIVA study, unpublished data). ${ }^{121}$

We disagree with the conclusion of a Cochrane review ${ }^{122}$ stating that there is a low-level of evidence for use of teriflunomide in relapsing-remitting MS and the reviewers' opinion about the methodological quality of the studies included. However, the low retention rate in the pivotal studies (around $70 \%$ ) possibly indicates a low therapeutic advantage. Teriflunomide has several limitations, including long persistence in the organism (for up to two years) and the need for fast elimination using cholestyramine or active charcoal in the event of pregnancy or adverse events. In our opinion, one major safety issue with teriflunomide is its teratogenic effect, which might limit its use, especially in female MS patients in the reproductive age group. ${ }^{112}$

Severe liver injury, including fatal liver failure, has been reported in patients treated with leflunomide. A similar risk would be expected for teriflunomide, given that the recommended doses for teriflunomide and leflunomide provide similar plasma concentrations of teriflunomide. As a consequence, teriflunomide is contraindicated in patients with hepatic impairment, and it is mandatory to monitor transaminase and bilirubin levels. Special attention should be paid to comedication with other potentially hepatotoxic drugs. In clinical trials, if alanine transaminase elevation was more than three times the upper limit of normal on two consecutive tests, teriflunomide was discontinued and patients underwent accelerated elimination.

There are insufficient data to evaluate rare or long-term adverse events, such as cancer and opportunistic infections. Two cases of PML during treatment with leflunomide in rheumatoid arthritis are described in more than 1.9 million patient-years of exposure. ${ }^{113}$ The risk of MS reactivation (or rebound) after drug discontinuation has not yet been assessed. Compared with other disease-modifying drugs, teriflunomide might not be safe or efficacious enough to be a first choice in naïve patients.

\section{Oral dimethyl fumarate}

Oral dimethyl fumarate (Fumaderm ${ }^{\circledR}$, Fumapharm AG, Luzern, Switzerland) has been used in Europe for more than 30 years to treat psoriasis. ${ }^{123,124}$ Dimethyl fumarate appears to have immunomodulatory and neuroprotective effects, possibly through an antioxidant effect determined by activation of nuclear factor (erythroid-derived 2)-like 2. ${ }^{124-126}$ Dimethyl fumarate does not cause significant immunosuppression. In March 2013, dimethyl fumarate (as Tecfidera ${ }^{\circledR}$, Biogen Idec) was approved by the FDA on the basis of randomized, controlled clinical Phase III trials (DEFINE and CONFIRM). ${ }^{127,128}$ The medical use of dimethyl fumarate appears safer than its industrial use, where it provoked eczematous burns in hundreds of people through skin contact in several European cities. ${ }^{129}$ 
A Phase II study (240 mg three times daily), ${ }^{130}$ and two randomized, controlled Phase III clinical trials (DEFINE and CONFIRM, $240 \mathrm{mg}$ twice or three times daily versus placebo) showed significant reduction in the relapse rate at two years and neuroradiological efficacy. ${ }^{127,128}$

In the CONFIRM trial, glatiramer acetate was also used as an active comparator and reduced the annualized relapse rate by $29 \%$ compared with the $51 \%$ reduction observed for dimethyl fumarate (higher dosage). According to a preliminary analysis, patients treated with dimethyl fumarate in the two Phase III clinical trials also reported a better quality of life. ${ }^{131}$

Although some inferences on long-term safety and tolerability can be derived from the use of systemic fumaric acid esters in psoriasis, the different treatment regimens (continuous versus intermittent) do not allow definite conclusions. A small $(n=66)$ study found no significant long-term adverse events and established the safety of fumarate in psoriasis with a follow-up period of up to 14 years (around $40 \%$ for at least one year, around $20 \%$ for $10-14$ years). ${ }^{132}$

In the pivotal trials (DEFINE and CONFIRM), common adverse events were nausea, abdominal pain, diarrhea, facial flushing, lymphopenia, eosinophilia, and hepatotoxicity (transaminase elevations). There have been no cases of malignancy or opportunistic infections. However, some concerns have been raised recently concerning the occurrence of PML in patients with psoriasis who were treated with fumarates. ${ }^{133-135}$

One of the advantages of dimethyl fumarate is the oral route of administration, which might enhance adherence. On the other hand, if flushing and gastrointestinal symptoms are not managed adequately, they might provoke early discontinuation. Addition of pentoxifylline or acetylsalicylic acid has been shown to be efficacious in reducing symptoms of flushing in patients with psoriasis. ${ }^{136} \mathrm{~A}$ randomized, doubleblind study is ongoing to evaluate the effects of aspirin or slow dose titration on reducing flushing and gastrointestinal events due to dimethyl fumarate in healthy volunteers. ${ }^{137}$

If safety and efficacy data from Phase III studies are confirmed to five years by the ongoing extension study (ENDORSE), ${ }^{138}$ dimethyl fumarate will be destined for success as a first-line treatment, compared with first-line injectable therapies. ${ }^{139}$

\section{Nonspecific immune suppressants Azathioprine}

Azathioprine is the most widely used immunosuppressant in MS, even if it is not approved in the US or in most
European countries. ${ }^{140}$ It is generally used at a dose of $2.5-3 \mathrm{mg} / \mathrm{kg} /$ day or lower in the event of hematological (white blood cell count $<3000$, lymphocyte count $<1000 / \mathrm{mm}^{2}$, or mean cell volume $>100$ ) or liver toxicity.

A Cochrane meta-analysis reported that azathioprine was effective in reducing relapses and progression of disability during a follow-up period of up to three years. ${ }^{141}$ However, this meta-analysis was based on trials judged as having a high to moderate risk of bias. Moreover, a large proportion of patients included were diagnosed as having progressive disease.

Efficacy with regard to MRI parameters was found in 14 patients with relapsing-remitting MS evaluated by monthly scans for six months before and after initiation of treatment. ${ }^{142}$ The more frequent adverse events are gastrointestinal intolerance, infections (especially of the urinary or respiratory tract), pancreatic and hepatic toxicity, and bone marrow suppression. ${ }^{143}$ Myelosuppression caused by azathioprine can be related to thiopurine S-methyltransferase deficiency, an autosomal recessive trait causing excessive accumulation of thioguanine nucleotides in hematopoietic tissues. ${ }^{140}$ As a consequence, periodic hematological examinations and dose adjustment are mandatory.

It would seem reasonable to recommend thiopurine methyltransferase testing when patients are not achieving their target white blood cell count despite adequate weightbased dosing, to ascertain unfavorable metabolism, which is unlikely to result in therapeutic efficacy. ${ }^{144}$

A possible increase in risk of malignancy was suggested only by treatment duration beyond ten years or a cumulative dose exceeding over 600 g. ${ }^{145}$ In particular, a risk of lymphoma of around one per 1000 was suggested by a study in patients with rheumatoid arthritis under long-term treatment with azathioprine. ${ }^{146}$ In conclusion, azathioprine should be used only in patients without other therapeutic options because of its unclear risk-benefit balance.

\section{Methotrexate}

Methotrexate is an antimetabolite approved in several countries for the treatment of rheumatoid arthritis, meningeal leukemia, and a variety of other malignancies. Long-term administration of methotrexate can be associated with serious adverse events, in particular hepatic fibrosis, but also lung, bone marrow, and kidney toxicities, as well as skin reactions. In rare instances hemorrhagic enteritis and death for intestinal perforation have been reported. Therefore in case of gastrointestinal symptoms such as diarrhea and ulcerative stomatitis, treatment should be stopped. An increased risk of opportu- 
nistic infections is possible. At the low doses used in MS, methotrexate is well tolerated and has an acceptable safety profile. Concomitant folate supplementation is recommended by some. Published studies are inconclusive, and the actual effectiveness of methotrexate in the treatment of MS has not been established. ${ }^{140}$ Well designed trials in relapsing-remitting MS are lacking. Use of methotrexate should be limited to cases unresponsive to approved drugs which in relapsingremitting MS is negligible.

\section{Cyclophosphamide}

Cyclophosphamide is an alkylating agent that binds to DNA, interfering with mitosis and the cell cycle. It has been used in various malignancies. Cyclophosphamide has immunosuppressive and immunomodulating properties and may exert a local immunomodulatory and immunosuppressive effect on the aberrant ectopic lymphatic tissue which has been related to disease progression. ${ }^{147,148}$ Cyclophosphamide is usually administered via the intravenous route monthly, and is well tolerated by most patients. ${ }^{149}$ Efficacy results of studies are often conflicting in relapsing-remitting MS. The greatest benefits may be seen in younger patients ( $<40$ years) with an aggressive course refractory to treatment. ${ }^{149}$

Common adverse events are alopecia, nausea/vomiting, transient myelosuppression, amenorrhea, oligo/azoospermia and hemorrhagic cystitis. Hemorrhagic cystitis occurs in about $4.5 \%$ of MS patients treated with cyclophosphamide, and can be prevented by increasing fluid intake and administration of uromitexan. Particular attention should be paid to patients with bladder dysfunction, and catheterization during infusion should be recommended if post-void residual is suspected. Cyclophosphamide increases the risk of bladder cancer which is favored by toxic cystitis, chronic urinary tract infections related to bladder dysfunction, and permanent catheterization. ${ }^{148}$ Bladder carcinoma can occur up to 17 years post-treatment and has been associated with a cumulative cyclophosphamide dosage of $>100 \mathrm{~g}$ in patients with rheumatologic disorders. ${ }^{150,151}$ Therefore, long-term surveillance in exposed patients should be carried out, including periodic urinary cytology and annual cystoscopy in selected cases. The risk of amenorrhea is between $33 \%$ and $44 \%$ in MS patients treated with cyclophosphamide, so women with child-bearing potential should be adequately informed. Azoospermia is related to the cumulative dose of cyclophosphamide, but it is unknown whether this is reversible or permanent.

Although data on humans are lacking, cyclophosphamide is teratogenic in animals, so should be discontinued before conception. ${ }^{148}$ Cyclophosphamide may also increase the risk of infection. Patients treated with cyclophosphamide should be instructed to avoid contact with patients with infectious diseases and to avoid live vaccines, particularly during the nadir period. ${ }^{149}$

Although extensive experience with cyclophosphamide in MS patients has been accrued in the past 40 years, conclusive efficacy data are lacking. Cyclophosphamide has not been approved for use in MS by the main regulatory agencies.

Cyclophosphamide at lower doses in combination with IFN $\beta$ appears to be effective and safe. ${ }^{152,153}$ At high doses, cyclophosphamide is used in autologous hematopoietic stem cell transplantation to mobilize peripheral blood progenitor cells, but the use of immunoablative doses as an alternative to other aggressive approaches, such as autologous hematopoietic stem cell transplantation or alemtuzumab, has not been investigated in controlled clinical trials.

Although the efficacy data are less convincing, cyclophosphamide may be preferred to methotrexate as induction therapy in rapidly progressing patients, because of the differential risk for leukemia. ${ }^{63}$ However, it has to be remembered that previous use of nonselective immunosuppressive drugs increases the risk of PML in natalizumab-treated patients. Cyclophosphamide should also be considered in the event that approved first-line and second-line drugs fail or when fingolimod, natalizumab, or methotrexate are contraindicated. ${ }^{147}$

\section{Experimental agents}

In the era of new oral agents, the use of injectables has become less appealing. Therefore, companies developing IFN $\beta$, analogous to what happened in hepatology, have devised new formulations requiring less frequent injection. In particular, PEGylation, a technique by which one or several molecules of polyethylene glycol (PEG) are covalently linked to a drug, extends the half-life of IFN $\beta$ - $1 \mathrm{a}$, thus allowing a reduction in the frequency of injection to once every two or four weeks. The lower frequency of administration might ameliorate adherence.

Preliminary studies have shown that PEGylated interferon beta-1a (PEG-IFN) is well tolerated, with mild and transient reduction in the absolute number of neutrophils and lymphocytes. The most common adverse event described is a flu-like syndrome and redness at the injection site. ${ }^{154,155}$ Cases of cutaneous sarcoidosis have been described after PEG-IFN injection. ${ }^{156} \mathrm{~A}$ further concern is toxicity, because interruption of treatment will not lead to rapid drug elimination. 


\section{New oral drugs}

\section{Laquinimod}

Laquinimod (quinolone-3-carboxamide) is an oral immunomodulatory agent with promising neuroprotective and anti-inflammatory effects. ${ }^{157}$ Laquinimod has shown in the Phase IIb trials and extension studies to have a good safety profile, and the higher dose of $0.6 \mathrm{mg}$ gave better results on MRI activity. The lower dose of $0.3 \mathrm{mg}$ did not show significant benefits. ${ }^{158-160}$ In the Phase III ALLEGRO and BRAVO studies, the relapse rate was not significantly decreased, but progression of disability and brain atrophy were significantly delayed by laquinimod $0.6 \mathrm{mg} /$ day. ${ }^{161,162} \mathrm{In}$ the ongoing CONCERTO study, the safety and efficacy of the higher dose of $1.2 \mathrm{mg}$ will be compared with laquinimod $0.6 \mathrm{mg}$ and placebo. So far, laquinimod seems well tolerated. ${ }^{163}$ The most common adverse events are abdominal pain, back pain, cough, and reversible liver toxicity. ${ }^{161}$ If the favorable safety profile is maintained at higher doses, with higher efficacy, laquinimod might represent a good option as first-line treatment, especially in patients showing progression from the early phase and in those with concomitant disease.

\section{Monoclonal antibodies}

\section{Alemtuzumab}

Previously known as campath-1H, alemtuzumab (Lemtrada ${ }^{\circledR}$, Genzyme) is a humanized monoclonal antibody to CD52 under scrutiny for licensing to treat relapsing-remitting MS. It is administered as an intravenous infusion five times in the first year and three times in the second year. Further cycles are given only in the event of reactivation of MS. Alemtuzumab compared with subcutaneous high-dose, high-frequency IFN $\beta$ - $1 \mathrm{a}$, in one Phase II trial ${ }^{164}$ and in two Phase III trials, ie, CARE-MS I ${ }^{165}$ and CARE-MS II, ${ }^{166}$ not only reduced the relapse rate but also decreased the accumulation of disability. ${ }^{167}$ An extension of the Phase II trial showed superiority of alemtuzumab compared with IFN $\beta$-1a for up to five years. ${ }^{168}$ The results of the CARE-MS II trial (untreated patients with early relapsing-remitting MS, Expanded Disability Status Scale $\leq 3.0$ and disease duration three years or less) strengthen the hypothesis that immunotherapies are more effective if given early. Alemtuzumab can cause an immediate infusion reaction, characterized by rash, headache, a flu-like syndrome, and transient recurrence of MS symptoms, which are easily controlled using corticosteroids, antihistamines, and paracetamol. Mild-to-moderate respiratory and urinary tract infections are more common in patients receiving alemtuzumab than in those receiving IFN $\beta$, but serious opportunistic infections are rare. Alemtuzumab has not been associated with cancers, and the three cases of thyroid papillary carcinoma which occurred during Phase III trials are considered to be incidental. ${ }^{165}$ The main serious adverse event during treatment with alemtuzumab was the appearance of novel autoimmune diseases, probably as a complication of immune reconstitution after lymphocytopenia. The most serious adverse event was thrombocytopenic purpura, which occurred in $2.8 \%$ of patients receiving alemtuzumab in the Phase II CAMMS223 trial, and was more frequent in the high-dose group (24 mg) and fatal in one patient, who died following a brain hemorrhage. After this case and two further reports, administration of alemtuzumab was stopped from September 2005 to May 2007. ${ }^{164}$ Immune reactions occurred in $20 \%-30 \%$ of patients as hypothyroidism or hyperthyroidism, frequently as Grave's disease, over five years. Other secondary autoimmune diseases observed were autoimmune hemolytic anemia and Goodpasture's disease. ${ }^{167,168}$ Given that autoimmune reactions can develop months to years after treatment, patient education, monthly blood cell counts, and three-monthly thyroid function tests are recommended for some years after cessation of treatment. Similar to other biological drugs, ${ }^{169-174}$ although humanized, alemtuzumab induces binding and neutralizing antibodies in up to $70 \%$ of patients after the second cycle. It is possible to prevent alemtuzumab immunogenicity by undertaking pretreatment with a modified version of alemtuzumab which no longer binds to its target and induces tolerance to alemtuzumab itself. ${ }^{167}$ Alemtuzumab induces long-term immunosuppression which can be difficult to manage in the event of adverse reactions. Long-term safety data need to be carefully considered.

In conclusion, alemtuzumab appears to be a very effective treatment for relapsing-remitting MS, but has a more complex safety profile than the current first-line therapies. There is still debate about the cases in which alemtuzumab should be used, ${ }^{167}$ but it may be used as an induction therapy in aggressive relapsing-remitting MS or as a third-line therapy in patients refractory to other disease-modifying drugs.

\section{Daclizumab}

Daclizumab (Zenapax ${ }^{\circledR}$, Roche Basel, Switzerland) is approved as an add-on to immunosuppressive regimens for preventing allograft rejection in renal transplantation. In the Phase II CHOICE ${ }^{174}$ and SELECT ${ }^{175}$ (where the daclizumab high-yield process [DAC-HYP] formulation was used) studies, daclizumab reduced relapses and the risk of progression to permanent disability. DECIDE is an ongoing Phase III trial comparing DAC-HYP and Avonex. ${ }^{176}$ Daclizumab is generally well tolerated, and the most common adverse 
events are skin rashes, liver toxicity, lymphadenopathy, and infection, all of which are generally mild. Patients treated with daclizumab may be more susceptible to primary infections, due to the inhibitory effect on $\mathrm{T}$ cell priming. Long-term follow-up of a larger number of patients will clarify any safety concerns. ${ }^{171,172}$

\section{Rituximab}

Rituximab is a monoclonal antibody that selectively reduces CD20+ B lymphocyte levels. About 10 years ago, rituximab was approved by the FDA for the treatment of some forms of lymphoproliferative disease. It is also approved for the treatment of rheumatoid arthritis, and is used in vasculitis ${ }^{177}$ and Devic's disease. ${ }^{178}$ In HERMES, a randomized, doubleblind, controlled Phase II clinical trial, administration of rituximab $1000 \mathrm{mg}$ on days 1 and 15 achieved a significant reduction in MRI activity and relapse rate in relapsingremitting MS. ${ }^{169,179}$

In the experience of rituximab in MS, including the OLYMPUS study which included patients with primary progressive MS, several infusion-associated adverse events have been reported, which were mostly mild to moderate in severity. ${ }^{180}$ These included headache, back pain, depression, limb pain, general pain, burning sensation, pruritus, and rash. The side effects described with rituximab in MS patients were dyspnea, muscle spasms, fever, chills, itching, diarrhea, flushing, cystitis, and bronchitis. ${ }^{177}$ In HERMES, three severe adverse events were reported in the rituximab arm, ie, ischemic coronary artery syndrome, malignant thyroid neoplasm, and severe acute progression of MS (one case each). Other serious adverse events were reported in similar proportions in the placebo and rituximab groups, including infections, although sinusitis and urinary tract infections were more common in the rituximab group. No clinically significant opportunistic infections were reported. Two serious infection-related adverse events (gastroenteritis and bronchitis) in the rituximab group resolved without sequelae.

As with natalizumab, the most worrisome adverse event with rituximab is PML. Fifty-seven cases of PML in rituximab-treated patients negative for human immunodeficiency virus (90\% with lymphoproliferative disease) were reported in 2009. ${ }^{181}$ Other rituximab-associated cases of PML were reported in patients with rheumatic disease. ${ }^{182}$

To our knowledge, no cases of PML have been reported in patients with MS treated using rituximab. The overall and long-term risk of rituximab-associated PML in patients with MS has yet to be determined. ${ }^{183}$ The patent for rituximab expires in the US in 2015. This will heavily influence the decision to launch a Phase III trial, given that the interest of the pharmacologic industry has shifted to new molecules, such as ocrelizumab.

\section{Ocrelizumab}

Ocrelizumab is a recombinant humanized monoclonal antibody against CD20 B cells. In a placebo-controlled Phase II trial, low-dose (600 mg) and high-dose (2000 mg) ocrelizumab was compared with IFN $\beta$-1a once weekly in patients with relapsing-remitting MS, and showed efficacy with regard to MRI parameters and a decreased relapse rate. ${ }^{184}$

Compared with rituximab, ocrelizumab has an increased cytotoxic effect and is expected to be less immunogenic with a potentially more favorable risk-benefit profile, although this does not appear to be the case from recent reports. ${ }^{184}$ The incidence of serious adverse events in the Phase II study were similar in the ocrelizumab, placebo, and IFN $\beta$-1a groups. However, one patient in the ocrelizumab $2000 \mathrm{mg}$ group died of systemic inflammatory response syndrome. ${ }^{14}$ In several rheumatoid arthritis and systemic lupus erythematosus trials, high rates of serious opportunistic infections were observed in patients treated with ocrelizumab, some resulting in death. Given that the morbidity associated with ocrelizumab in patients with rheumatoid arthritis or systemic lupus erythematosus outweighs the benefits observed, clinical development programs were discontinued. ${ }^{185,186}$ The higher incidence of infections during the trials is probably ascribable to the fact that, in all the patients with arthritis, ocrelizumab was used as an add-on to immunosuppressive drugs such as methotrexate, leflunomide, cyclophosphamide, and corticosteroids. ${ }^{187}$ There is debate concerning the safety profile of ocrelizumab in patients with MS. Further large long-term studies are needed to explore its advantages compared with rituximab and the benefit-risk profile of this humanized monoclonal antibody in MS. ${ }^{184,188}$

\section{Combination therapy}

Because MS is a multifactorial disease with complex etiopathogenetic mechanisms, it is reasonable to evaluate, in well designed clinical trials, efficacy and safety of drugs with different mechanisms of action used in combination, in order to abolish all disease activity, compatibly with safety concerns. Higher efficacy comes at a cost and might make combination therapy unadvisable. Up until recently, none of the combination studies performed with IFN $\beta$, except in combination with cyclophosphamide, had shown unequivo- 
cal evidence of benefit, including combinations involving statins, natalizumab, and azathioprine. ${ }^{189}$

CombiRx, a multicenter, randomized, three-arm Phase III trial evaluating the superiority of a once-weekly combination of IFN $\beta$-1a and glatiramer acetate versus each agent alone and a matching placebo, confirmed the safety of this combination therapy, but clinical efficacy outcomes were insufficient to warrant its endorsement, even though the combination was more effective than either of the two drugs used alone with regard to MRI outcomes. It will be interesting to evaluate the effect of this combination on clinical outcomes during longer-term follow-up.

As stated earlier, nonspecific immunosuppressants have been evaluated in association with IFN $\beta$ in several trials. Cyclophosphamide, in particular, proved effective in terms of clinical and radiological outcomes in patients with rapidly worsening disease not responsive to IFN $\beta$ alone. ${ }^{190-192}$ In contrast, methotrexate showed no significant benefit as add-on therapy compared with IFN $\beta$-1a monotherapy. ${ }^{193}$ Methotrexate has been used in association with intramuscular IFN $\beta$-1a (unpublished results, personal involvement in the trial) or, more frequently, in sequential association, and demonstrated a reduction in clinical and especially MRI activity. ${ }^{194,195}$

The putative immunomodulatory effect of statins has been studied in association with glatiramer acetate and IFN $\beta$ in MS. A recent meta-analysis showed that addition of statins to IFN $\beta$ therapy has no benefit in MS patients. ${ }^{196}$ Vitamin D has been evaluated as an add-on to routine disease-modifying drugs, with no significant effect on disability or relapse rate demonstrated, but a positive effect was seen on MRI activity and without significant adverse events. ${ }^{197,198}$ Estrogens in association with IFN $\beta$ were found to have a positive effect on MRI parameters. ${ }^{199}$

The SENTINEL study demonstrated that natalizumab plus IFN $\beta$ was superior to IFN $\beta$ alone, but this could be ascribable to a net effect of natalizumab rather than to a positive synergistic effect. However, this association has been proscribed since the occurrence of the first cases of PML among patients treated with IFN $\beta .^{65}$ The present data on natalizumab-associated PML do not allow definitive conclusions, but it seems that the role of IFN $\beta$ in the development of PML was minor, if any. A Phase III study evaluated the efficacy of rituximab as an add-on in patients with relapsing-remitting MS and an inadequate response to IFN $\beta$ or glatiramer acetate, and showed a significant reduction in gadolinium-enhancing lesions and in the annualized relapse rate after treatment with rituximab. ${ }^{200}$
In conclusion, a risk-benefit evaluation is mandatory in every patient considering combination therapy, either sequential or simultaneous, especially when using drugs posing potential safety concerns. Possible synergistic toxicity has to be considered carefully.

\section{Discussion}

The therapeutic landscape for MS is now varied, requiring thorough evaluation of the potential risks and benefits of treatment with each of the agents available. Most patients with MS appreciate clarity and have a strong desire to be informed and share therapeutic decision-making. ${ }^{201,202}$ Decision-making under risk, in MS patients, is modified. ${ }^{203}$ Therefore, it seems crucial to inform patients that MS could influence management of counterfactual information and risk, and help them to overcome this obstacle through a good and trusting relationship. Health care professionals should not only evaluate the risks associated with therapy, but also the natural history of the untreated disease. They should ascertain each patient's needs, goals, values, and fears. ${ }^{204,205}$ Social and cultural background can influence perception and learning about the disease and its treatment, and aid patient decision-making. For example, it has been shown that Germans prefer to take an active role, whereas Italians are more passive-collaborative. ${ }^{206}$ Communication of the diagnosis and treatment suggestions are crucial steps. For a trusting and collaborative relationship, it is very important to educate the patient on the disease process, its natural history without treatment, and the risks and benefits of the various therapies available.

Patient empowerment is crucial for enhancing patient involvement in reporting outcomes, both at the clinical trial stage of drug development and during post-marketing follow-up. ${ }^{207}$ Given that patients can learn in many different ways, it can be useful to explain the disease and its treatment with the aid of visual tools. ${ }^{205}$ The effectiveness of an add-on information aid for newly diagnosed MS patients was demonstrated in a randomized controlled trial. ${ }^{208}$

Patient empowerment is also meaningful from an economic perspective. In this appraisal, we have not addressed the cost-effectiveness of disease-modifying drugs. However, the issues of the treatment costs and safety monitoring should be introduced into the treatment decision-making algorithm. Genuine patient participation in health care decision-making and true patient involvement in treatment choices cannot be reached without a cost-effectiveness analysis and in consideration of the limited resources and increasingly expensive health technology worldwide. 
Finally, to obtain maximum adherence with therapy, the physician, when proposing treatment, should also consider the biopsychosocial aspects of medical care, discuss them with the patient, and finally make a shared decision. Johnson et al showed that the most important factor for patients in their treatment preferences was to delay progression of disability. Among the risks, the most feared was PML, followed by liver failure and leukemia. Patients usually prefer higher efficacy against the risk of adverse events and tend to dismiss low frequency risks. ${ }^{209}$

The therapeutic landscape for MS is enlarging rapidly, thanks to the availability of new oral agents with a favorable risk-benefit profile and possibly new monoclonal antibodies. Moreover, it is now possible to stratify the risk of serious complications, such as PML, with the help of serological tests and clinical and radiological evaluation. Unlike in the past, natalizumab is now used not only as a rescue therapy in patients who are nonresponsive to first-line diseasemodifying drugs, but also as first-line therapy, especially in patients with a negative $\mathrm{JC}$ virus test and very active disease. ${ }^{210,211}$ Continuous re-evaluation of each patient's overall situation is mandatory to manage their disease and needs at an individual level.

\section{Risk-benefit considerations}

\section{First-line drugs}

The balance between risks and benefits is favorable for all first-line MS drugs approved in Europe. The shared decision about which drug to use first is strongly influenced by the experience of the prescribing neurologist, and also by the comorbidities, lifestyle, and clinical and radiological characteristics of each individual patient. The published evidence indicates that no new signals have been identified after more than 20 years of using these agents. Depression does not seem to be a limiting factor in the use of IFN $\beta$. On the contrary, in the long run, injection-related skin reactions, such as lipoatrophy, can hamper drug adsorption, especially with high-dose, high-frequency subcutaneous IFN $\beta$. The same holds true for glatiramer acetate. Liver enzyme elevations or leukopenia can prevent utilization of IFN $\beta$ at the full dose, potentially decreasing efficacy. All these considerations are routinely taken into account in clinical practice, and have led to optimization of treatment and adherence.

It needs to be ascertained whether the new oral diseasemodifying drugs have a positive benefit-risk ratio compared with the established first-line disease-modifying drugs. While the availability of oral therapies has been much awaited by physicians, and even more so by patients, we believe that neurologists, when proposing use of such disease-modifying drugs, should discuss the efficacy, safety, tolerability, adherence, and general feasibility of these treatments with the patient, along with the issues of safety monitoring (and possible unknown long-term or rare adverse events), pregnancy planning, and concomitant medications. ${ }^{212}$

\section{Second-line drugs in Europe}

The use of higher-risk second-line drugs has to be evaluated, not only in terms of potentially better efficacy but also in terms of potentially unacceptable side effects. ${ }^{213}$ To enable an evidence-based decision about second-line treatment, headto-head clinical trials comparing the efficacy, tolerability, and safety of natalizumab and fingolimod should be performed, but have not been done as yet. Observational studies with appropriate statistical methodology will be helpful, but are also unavailable at the moment. Among the second-line drugs, the choice between natalizumab and fingolimod involves several considerations. First, as most neurologists would agree, natalizumab has higher efficacy in very aggressive cases. Second, the risk of PML can be stratified and JC-negative cases can be treated at a significantly lower risk. Third, after initiation of treatment (which is a complex process), the convenience of fingolimod is higher, but this might lead to difficulty in monitoring patients, especially in the US. Fourth, shifting from natalizumab to fingolimod early after discontinuation of the former does not prevent reactivation of disease, although a good clinical and radiological response can be obtained in many patients, after a run-in of several months.

\section{Early treatment and shifting therapy}

When considering the present and future treatments for relapsing-remitting MS, one of the most challenging issues is when, why, and with what to treat a patient or when to substitute a drug. Opinions have changed in the time interval between the earlier disease-modifying drug era and the present. ${ }^{29,214-224}$ Treatment aims at maintaining disease stability and preventing relapses and progression of disability. At diagnosis, age, gender, MRI parameters, response to steroid treatment, presence of sequelae, and the systems involved are weighted heavily in the clinical decision-making process. Although there is consensus about treating early, the time interval between diagnosis and treatment might differ according to the severity and aggressiveness of the disease and findings on MRI scan. Two main strategies can be considered, ie, induction versus escalation. Induction is preferred in aggressive cases, and usually the first drug chosen is a 
second-line or third-line one, to be used for a limited period of time only. Efficacy should persist after discontinuation of the run-in period using the less risky drug. This strategy has worked with conventional nonselective immunosuppressants, but cannot be proposed for the present second-line agents, such as natalizumab and fingolimod which, being selective and not cytotoxic, are associated with reactivation of disease soon after discontinuation. In contrast, escalation is usually used in nonaggressive cases, where safety and quality of life are paramount. In these cases, first-line treatment may lead to full efficacy at low risk. However, if this is not the case, prompt action should be taken to prevent tissue damage and minimize the risk of sequelae in terms of residual inflammatory activity and relapses. Therefore, the present consensus is that full efficacy should be sought with the first treatment, but that less stringent criteria can be used when considering further treatment, given that complete absence of disease activity cannot be achieved in aggressive cases.

The definition of "responder" is still controversial, although several papers have addressed this issue since the early 2000s. ${ }^{225-234}$ The main point is sharing the present knowledge about the risks and benefits of the proposed drug with the patient, along with the implications if treatment fails and possible interference with future treatment, ie, the risk of PML with natalizumab is enhanced by previous use of immunosuppressants and the risk of hepatotoxicity or bone marrow toxicity is increased using long-acting drugs, and lipoatrophy or subcutaneous nodules limit the use of other subcutaneous injectables in shifts to and from glatiramer acetate and subcutaneous IFN $\beta$.

\section{Pregnancy in women with MS}

Unlike in earlier times when pregnancy was discouraged, we are now fully aware that, in the era of disease-modifying drugs and with epidemiological data suggestive of the possible positive effects of pregnancy on MS, women with MS need clear indications on how to plan pregnancy once treatment has been started. ${ }^{235}$ In the US, the National Multiple Sclerosis Society has issued recommendations suggesting that women discontinue treatment one full menstrual cycle prior to attempting conception. These recommendations also suggest resumption of treatment soon after delivery if breastfeeding is not planned. Similar guidelines are lacking in Europe. ${ }^{236}$ We believe that one of the most difficult tasks for neurologists will be counseling women of childbearing age at the time of diagnosis, given that the choice of treatment has to take into account the potential risks not only of becoming pregnant during treatment, but also the risk of reactivation of
MS after discontinuation of treatment, especially if this has to be planned in advance and without a guarantee that pregnancy will ensue promptly. The possibility of a rebound effect also has to be taken into account. This is particularly important given that in vitro fertilization appears to increase the risk of relapse. ${ }^{237}$ After the PRIMS study addressing the issue of the consequences of pregnancy in terms of the long-term prognosis, several publications have suggested that it is safer for the woman and child not to interrupt first-line injectable therapy, especially glatiramer acetate, until a pregnancy test is positive. ${ }^{19,238-242}$ However, it is unclear whether a similar recommendation should be made for women receiving natalizumab. In the absence of data from pregnancy registries, we would suggest to discontinue treatment with fingolimod, teriflunomide, and other conventional immunosuppressive drugs with potential teratogenic effects before conception, with the possible exception of azathioprine, which appears to have minimal teratogenic effects. ${ }^{243}$ No data are available, to our knowledge, on dimethyl fumarate, alemtuzumab, or other monoclonal antibodies as yet not approved for use in MS. The issue of symptomatic treatment would also be important but is beyond the scope of this review. In the modern era of patient-centered medicine, the thoughts and fears of women should guide us through a shared decision-making process where the woman has a central role. Finally, it is controversial whether pregnant women should be excluded from clinical trials. $^{236,244}$

\section{Pediatric MS}

Onset of MS occurs before the age of 16 years in 3\%-5\% of cases, and the disease is certainly underdiagnosed before the age of 10 years. The course of the disease in this age group tends to be relapsing-remitting, with a higher relapse rate than in adult cases and prominent cognitive impairment. Although time to progression of disability is longer, disability occurs at an earlier age. ${ }^{245}$ Given all this, it is crucial to start treatment early. Balancing the expected risks and benefits is a challenging exercise. One of the major difficulties is the need to inform both the child and the parents, and to reach a compromise between their different expectations, while avoiding being falsely reassuring or excessively frightening. The risk of poorly controlled MS as opposed to potential adverse events heightens the need for continued adherence with therapy.

No disease-modifying drug has been approved for use in the pediatric population (younger than 12 years of age); however, clinical practice, case reports, and observational studies have not identified any novel or unexpected adverse events 
using traditional disease-modifying drugs or natalizumab. Response to treatment appears to be good. ${ }^{246-250}$ As recommended by the International Pediatric Multiple Sclerosis Study Group in 2012, pediatric patients with MS should be included in clinical trials and in long-term follow-up studies in order to evaluate the safety and efficacy of emerging MS drugs in this age group..$^{251,252}$

\section{Comorbidities and comedications}

In adults, the need for symptomatic treatment and existence of comorbidities can increase the risk of adverse events, especially when the disease duration is long or disability is severe. Among other issues, the use of drugs impacting on the QT interval or the cytochrome P450 system has to be taken into account when prescribing fingolimod. Previous use of antiproliferative agents or concomitant use of other drugs with myelotoxic potential might enhance the toxic effects of immunosuppressive agents on the bone marrow. Like conventional immunosuppressive drugs in the past, teriflunomide might be particularly useful in patients with concomitant autoimmune disease. Dimethyl fumarate might be an appropriate choice in patients with MS and psoriasis who experience flare-ups of psoriasis during treatment with IFN $\beta$. It has still to be ascertained whether serial or simultaneous use of new and old disease-modifying drugs will favor the appearance of serious adverse events. ${ }^{129}$

\section{Treatment of MS and affective disorders}

Regardless of the treatment administered, psychiatric disorders, especially depression, are common in patients with MS, because of the psychosocial impact of the diagnosis and the associated disability, and are also biologically mediated by brain damage and the immunological and neurotrophic mechanisms involved in the pathogenesis of MS..$^{253-255}$ Thorough assessment of affective disorders is mandatory to minimize their consequences, especially with regard to treatment-related risks.

\section{Conclusion}

MS specialists need to know not only the specific risks and benefits of the individual drugs available, but also the potential drug interactions that can occur with simultaneous or serial combination therapy, and patients' comorbidities, preferences, and fears. These factors need to be put into perspective, considering also the risks of untreated disease in patients with different clinical and radiological characteristics.

In the widening therapeutic landscape, there is no single best treatment strategy, so therapy has to be tailored to the individual patient. This is a time-consuming task, rich in complexity and influenced by the attitude towards risk on the part of both the patient and the clinical team. The larger the MS drug market becomes, the harder it will be for clinicians to help patients decide on which therapeutic strategy to adopt. Every effort should be made to enhance empowerment of our MS patients. The final decision should always be left to the well informed patient. Although graphic representations of the relative benefit-risk ratio, with efficacy on the $y$ axis and burden of treatment on the $\mathrm{x}$ axis, have been proposed and presented at meetings, we believe that each factor (convenience, safety, tolerability, affordability) has a different weight for each patient and health care provider, and so have abandoned the idea of representing graphically the synthesis of our considerations. However, we do not believe that the quest for a highly efficacious and safe MS drug is over.

\section{Acknowledgment}

Eugenio Pucci would like to acknowledge the Associazione Marchigiana Sclerosi Multipla e Altre Malattie Neurologiche for supporting this research.

\section{Disclosure}

$\mathrm{AL}$ is a member of the advisory boards of Bayer Schering, Biogen Idec, Genzyme, and Merck Serono. She has received travel grants and honoraria from Allergan, Bayer Schering, Biogen Idec, Merck Serono, Novartis, Sanofi Aventis, and Teva, and research grants from Bayer Schering, Biogen Idec, Merck Serono, Novartis, Sanofi Aventis, and Teva. AL has also received travel and research grants from the Italian Association for Multiple Sclerosis and has been a consultant to Fondazione Cesare Serono. MdI, DT, and Erika Pietrolongo have received travel grants from Bayer Schering, Biogen Idec, Merck Serono, Novartis, Sanofi Aventis, and Teva, and their institution has received research grants from Bayer Schering, Biogen Idec, Merck Serono, Novartis, Sanofi Aventis, and Teva. In the last five years, Eugenio Pucci has received honoraria and travel grants for scientific and educational activities supported by Sanofi Aventis, UCB, Lundbeck, Novartis, Bayer Schering, Biogen Idec, Merck Serono, and Teva. MO has served as a consultant for UCB, Novartis, Lundbeck, Medtronic, Newron, and Boeringer Ingelheim.

\section{References}

1. Tremlett H, Zhao Y, Rieckmann P, Hutchinson M. New perspectives in the natural history of multiple sclerosis. Neurology. 2010;74: 2004-2015.

2. Lublin FD, Reingold SC. Defining the clinical course of multiple sclerosis: results of an international survey. National Multiple Sclerosis Society (USA) Advisory Committee on Clinical Trials of New Agents in Multiple Sclerosis. Neurology. 1996;46:907-911. 
3. Weinshenker BG, Bass B, Rice GP, et al. The natural history of multiple sclerosis: a geographically based study. I. Clinical course and disability. Brain. 1989;112(Pt 1):133-146.

4. Tremlett H, Devonshire V. Is late-onset multiple sclerosis associated with a worse outcome? Neurology. 2006;67:954-959.

5. Pittock SJ. Does benign multiple sclerosis today imply benign multiple sclerosis tomorrow: implications for treatment. Neurology. 2007;68:480-481.

6. Hawkins SA, McDonnell GV. Benign multiple sclerosis? Clinical course, long term follow up, and assessment of prognostic factors. J Neurol Neurosurg Psychiatry. 1999;67:148-152.

7. Langdon CW, Amato MP, Boringa J, et al. Recommendations for a Brief International Cognitive Assessment for Multiple Sclerosis (BICAMS). Mult Scler. 2012;18:891-898.

8. Benito-León J, Morales JM, Rivera-Navarro J, Mitchell A. A review about the impact of multiple sclerosis on health-related quality of life. Disabil Rehabil. 2003;25:1291-1303.

9. Vukusic S, Confavreux C. Natural history of multiple sclerosis: risk factors and prognostic indicators. Curr Opin Neurol. 2007;20:269-274.

10. Lublin FD. Clinical features and diagnosis of multiple sclerosis. Neurol Clin. 2005;23:1-15.

11. Trojano M, Paolicelli D, Tortorella C, et al. Natural history of multiple sclerosis: have available therapies impacted long-term prognosis? Neurol Clin. 2011;29:309-321.

12. Polman CH, Reingold SC, Banwell B, et al. Diagnostic criteria for multiple sclerosis: 2010 revisions to the McDonald criteria. Ann Neurol. 2011;69:292-302.

13. Trojano M, Pellegrini F, Fuiani A, et al. New natural history of interferon-beta-treated relapsing multiple sclerosis. Ann Neurol. 2007;61:300-306.

14. Phillips JT, Giovannoni G, Lublin FD, et al. Sustained improvement in Expanded Disability Status Scale as a new efficacy measure of neurological change in multiple sclerosis: treatment effects with natalizumab in patients with relapsing multiple sclerosis. Mult Scler. 2011;17:970-979.

15. The IFNB Multiple Sclerosis Study Group. Interferon beta- $1 \mathrm{~b}$ is effective in relapsing-remitting multiple sclerosis. I. Clinical results of a multicenter, randomized, double-blind, placebo-controlled trial. Neurology. 1993;43:655-661.

16. Paty DW, Li DK. Interferon beta-1b is effective in relapsing-remitting multiple sclerosis. II. MRI analysis results of a multicenter, randomized, double-blind, placebo-controlled trial. UBC MS/MRI Study Group and the IFNB Multiple Sclerosis Study Group. Neurology. 1993;43:662-667.

17. Jacobs LD, Cookfair DL, Rudick RA, et al. Intramuscular interferon beta-1a for disease progression in relapsing multiple sclerosis. The Multiple Sclerosis Collaborative Research Group (MSCRG). Ann Neurol. 1996;39:285-294.

18. PRISMS (Prevention of Relapses and Disability by Interferon beta-1a Subcutaneously in Multiple Sclerosis) Study Group. Randomised double-blind placebo-controlled study of interferon beta-1a in relapsing/ remitting multiple sclerosis. Lancet. 1998;352:1498-1504.

19. Amato MP, Portaccio E, Ghezzi A, et al. Pregnancy and fetal outcomes after interferon- $\beta$ exposure in multiple sclerosis. Neurology. 2010;75:1794-1802.

20. PRISMS Study Group and the University of British Columbia MS/MRI Analysis Group. PRISMS-4: long-term efficacy of interferon-beta-1a in relapsing MS. Neurology. 2001;56:1628-1636.

21. Durelli L, Verdun E, Barbero P, et al. Every-other-day interferon beta-1b versus once-weekly interferon beta-1a for multiple sclerosis: results of a 2-year prospective randomised multicentre study (INCOMIN). Lancet. 2002;359:1453-1460.

22. Panitch H, Goodin DS, Francis G, et al. Randomized, comparative study of interferon beta-1a treatment regimens in MS: the EVIDENCE Trial. Neurology. 2002;59:1496-1506.

23. Jacobs LD, Beck RW, Simon JH, et al. Intramuscular interferon beta-1a therapy initiated during a first demyelinating event in multiple sclerosis. CHAMPS Study Group. N Engl J Med. 2000;343:898-904.
24. Comi G, Filippi M, Barkhof F, et al. Early Treatment of Multiple Sclerosis Study Group. Effect of early interferon treatment on conversion to definite multiple sclerosis: a randomised study. Lancet. 2001;357:1576-1582.

25. Kappos L, Traboulsee A, Constantinescu C, et al. Long-term subcutaneous interferon beta-1a therapy in patients with relapsing-remitting MS. Neurology. 2006;67:944-953.

26. Comi G, De Stefano N, Freedman MS, et al. Comparison of two dosing frequencies of subcutaneous interferon beta-1a in patients with a first clinical demyelinating event suggestive of multiple sclerosis (REFLEX): a phase 3 randomised controlled trial. Lancet Neurol. 2012;11:33-41.

27. Kappos L, Freedman MS, Polman CH, et al. Long-term effect of early treatment with interferon beta- $1 \mathrm{~b}$ after a first clinical event suggestive of multiple sclerosis: 5-year active treatment extension of the phase 3 BENEFIT trial. Lancet Neurol. 2009;8:987-997.

28. Shirani A, Zhao Y, Karim ME, et al. Association between use of interferon beta and progression of disability in patients with relapsingremitting multiple sclerosis. JAMA. 2012;308:247-256.

29. Trojano M, Pellegrini F, Paolicelli D, et al. Real-life impact of early interferon beta therapy in relapsing multiple sclerosis. Ann Neurol. 2009;66:513-520.

30. Bergamaschi R, Quaglini S, Tavazzi E, et al. Immunomodulatory therapies delay disease progression in multiple sclerosis. Mult Scler. May 31, 2012. [Epub ahead of print.]

31. Kister I, Chamot E, Cutter G, et al. Increasing age at disability milestones among MS patients in the MSBase Registry. J Neurol Sci. 2012;318:94-99.

32. Cohen JA, Antel JP. Does interferon beta help in secondary progressive MS? Neurology. 2004;63:1768-1769.

33. Goodin DS, Reder AT, Ebers GC, et al. Survival in MS: a randomized cohort study 21 years after the start of the pivotal IFN $\beta-1 b$ trial. Neurology. 2012;78:1315-1322.

34. Lugaresi A, Florio C, Brescia-Morra V, et al. Patient adherence to and tolerability of self-administered interferon $\beta$-1a using an electronic autoinjection device: a multicentre, open-label, phase IV study. $B M C$ Neurol. 2012;12:7.

35. Lugaresi A. RebiSmart ${ }^{\mathrm{TM}}$ (version 1.5) device for multiple sclerosis treatment delivery and adherence. Expert Opin Drug Deliv. 2013;10:273-283.

36. Goeb JL, Even C, Nicolas G, Gohier B, Dubas F, Garré JB. Psychiatric side effects of interferon-beta in multiple sclerosis. Eur Psychiatry. 2006;21:186-193.

37. Patten SB, Williams JV, Metz LM. Anti-depressant use in association with interferon and glatiramer acetate treatment in multiple sclerosis. Mult Scler. 2008;14:406-411.

38. Patti F, Amato MP, Trojano M, et al. Quality of life, depression and fatigue in mildly disabled patients with relapsing-remitting multiple sclerosis receiving subcutaneous interferon beta-1a: 3 -year results from the COGIMUS (Cognitive Impairment in Multiple Sclerosis) study. Mult Scler. 2011;17:991-1001.

39. Tremlett HL, Yoshida EM, Oger J. Liver injury associated with the beta-interferons for MS: a comparison between the three products. Neurology. 2004;62:628-631.

40. Manfredonia F, Pasquali L, Dardano A, Iudice A, Murri L, Monzani F. Review of the clinical evidence for interferon beta 1a (Rebif) in the treatment of multiple sclerosis. Neuropsychiatr Dis Treat. 2008;4:321-336.

41. Sørensen PS, Deisenhammer F, Duda P, et al. Guidelines on use of anti-IFN-beta antibody measurements in multiple sclerosis: report of an EFNS Task Force on IFN-beta antibodies in multiple sclerosis. Eur J Neurol. 2005;12:817-827.

42. Creeke PI, Farrell RA. Clinical testing for neutralizing antibodies to interferon- $\beta$ in multiple sclerosis. Ther Adv Neurol Disord. 2013;6:3-17.

43. Sandberg-Wollheim M, Kornmann G, Bischof D, Moraga MS, Hennessy B, Alteri E. The risk of malignancy is not increased in patients with multiple sclerosis treated with subcutaneous interferon beta-la: analysis of data from clinical trial and post-marketing surveillance settings. Mult Scler. 2011;17:431-440. 
44. Lebrun C, Debouverie M, Vermersch P, et al. Cancer risk and impact of disease-modifying treatments in patients with multiple sclerosis. Mult Scler. 2008;14:399-405.

45. Bornstein MB, Miller A, Slagle S, et al. A pilot trial of Cop 1 in exacerbating remitting multiple sclerosis. $N$ Engl J Med. 1987;317: $408-414$.

46. Johnson KP, Brooks BR, Cohen JA. Copolymer 1 reduces relapse rate and improves disability in relapsing-remitting multiple sclerosis: results of a phase III multicenter, double-blind placebo-controlled trial. The Copolymer 1 Multiple Sclerosis Study Group. Neurology. 1995;45:1268-1276.

47. Qizilbash N, Mendez I, Sanchez-de la Rosa R. Benefit-risk analysis of glatiramer acetate for relapsing-remitting and clinically isolated syndrome multiple sclerosis. Clin Ther. 2012;34:159-176.

48. Comi G, Filippi M, Wolinsky JS. European/Canadian multicenter, double-blind, randomized, placebo-controlled study of the effects of glatiramer acetate on magnetic resonance imaging measured disease activity and burden in patients with relapsing-remitting multiple sclerosis. Ann Neurol. 2001;149:290-297.

49. Comi G. Effect of glatiramer acetate on conversion to clinically definite multiple sclerosis in patients with clinically isolated syndrome (PreCISe study): a randomised, double-blind, placebo-controlled trial. Lancet. 2009;374:1503-1511.

50. Lublin FD, Cofield SS, Cutter GR, et al. Randomized study combining interferon and glatiramer acetate in multiple sclerosis. Ann Neurol. 2013;73:327-340.

51. Mikol DD, Barkhof F, Chang P, et al. Comparison of subcutaneous interferon beta-1a with glatiramer acetate in patients with relapsing multiple sclerosis (the REbif vs Glatiramer Acetate in Relapsing MS Disease [REGARD] study): a multicentre, randomised, parallel, openlabel trial. Lancet Neurol. 2008;7:903-914.

52. Cadavid D, Wolansky LJ, Skurnick J, et al. Efficacy of treatment of MS with IFNbeta-1b or glatiramer acetate by monthly brain MRI in the BECOME study. Neurology. 2009;72:1976-1983.

53. O’Connor P, Filippi M, Arnason B, et al. 250 microg or 500 microg interferon beta- $1 \mathrm{~b}$ versus $20 \mathrm{mg}$ glatiramer acetate in relapsing-remitting multiple sclerosis: a prospective, randomised, multicentre study. Lancet Neurol. 2009;8:889-897.

54. McGraw CA, Lublin FD. Interferon beta and glatiramer acetate therapy. Neurotherapeutics. 2013;10:2-18.

55. Ford C, Goodman AD, Johnson K, et al. Continuous long-term immunomodulatory therapy in relapsing multiple sclerosis: results from the 15-year analysis of the US prospective open-label study of glatiramer acetate. Mult Scler. 2010;16:342-350.

56. Giovannoni G, Southam E, Waubant E. Systematic review of disease-modifying therapies to assess unmet needs in multiple sclerosis: tolerability and adherence. Mult Scler. 2012;18:932-946.

57. Jongen PJ, Lehnick D, Sanders E, et al. Health-related quality of life in relapsing remitting multiple sclerosis patients during treatment with glatiramer acetate: a prospective, observational, international, multicentre study. Health Qual Life Outcomes. 2010;8:133.

58. Rauschka H, Farina C, Sator P, et al. Severe anaphylactic reaction to glatiramer acetate with specific IgE. Neurology. 2005;64: 1481-1482.

59. Baumgartner A, Stich O, Rauer S. Anaphylactic reaction after injection of glatiramer acetate (copaxone) in patients with relapsing-remitting multiple sclerosis. Eur Neurol. 2011;66:368-370.

60. Marriott JJ, Miyasaki JM, Gronseth G, O'Connor PW. Therapeutics and Technology Assessment Subcommittee of the American Academy of Neurology. Evidence Report: The efficacy and safety of mitoxantrone (Novantrone) in the treatment of multiple sclerosis: Report of the Therapeutics and Technology Assessment Subcommittee of the American Academy of Neurology. Neurology. 2010;74:1 463-1470.

61. Martinelli V, Radaelli M, Straffi L, Rodegher M, Comi G. Mitoxantrone: benefits and risks in multiple sclerosis patients. Neurol Sci. 2009; 30 Suppl 2:S167-S170.
62. Pascual AM, Téllez N, Boscá I, et al. Revision of the risk of secondary leukaemia after mitoxantrone in multiple sclerosis populations is required. Mult Scler. 2009;15:1303-1310.

63. Martinelli V, Cocco E, Capra R, et al. Acute myeloid leukemia in Italian patients with multiple sclerosis treated with mitoxantrone. Neurology. 2011;77:1887-1995.

64. Polman CH, O'Connor PW, Havrdova E, et al. A randomized, placebocontrolled trial of natalizumab for relapsing multiple sclerosis. $N$ Engl J Med. 2006;354:899-910.

65. Rudick RA, Stuart WH, Calabresi PA, et al. Natalizumab plus interferon beta-1a for relapsing multiple sclerosis. $N$ Engl J Med. 2006;354:911-923.

66. Pucci E, Giuliani G, Solari A, et al. Natalizumab for relapsing remitting multiple sclerosis. Cochrane Database Syst Rev. 2011;10: CD007621.

67. Havrdova E, Galetta S, Hutchinson M, et al. Effect of natalizumab on clinical and radiological disease activity in multiple sclerosis: a retrospective analysis of the Natalizumab Safety and Efficacy in RelapsingRemitting Multiple Sclerosis (AFFIRM) study. Lancet Neurol. 2009;8: 254-260.

68. Iaffaldano P, Viterbo RG, Paolicelli D, et al. Impact of natalizumab on cognitive performances and fatigue in relapsing multiple sclerosis: a prospective, open-label, two years observational study. PLoS One. March 23, 2012. [Epub ahead of print.]

69. Rudick R, Polman C, Clifford D, Miller D, Steinman L. Natalizumab: bench to bedside and beyond. JAMA Neurol. 2013;70:172-182.

70. Chen Y, Bord E, Tompkins T, et al. Asymptomatic reactivation of JC virus in patient treated with natalizumab. $N$ Engl J Med. 2009;361:1067-1074.

71. Schröder A, Lee DH, Hellwig K, et al. Successful management of natalizumab-associated progressive multifocal leukoencephalopathy and immune reconstitution syndrome in a patient with multiple sclerosis. Arch Neurol. 2010;67:1391-1394.

72. Bloomgren G, Richman S, Hotermans C, et al. Risk of natalizumabassociated progressive multifocal leukoencephalopathy. $N$ Engl J Med. 2012;366:1870-1880.

73. Trampe AK, Hemmelmann C, Stroet A, et al. Anti-JC virus antibodies in a large German natalizumab-treated multiple sclerosis cohort. Neurology. 2012;78:1736-1742.

74. Borriello G, Prosperini L, Mancinelli C, Giannì C, Fubelli F, Pozzilli C. Pulse monthly steroids during an elective interruption of natalizumab: a post-marketing study. Eur J Neurol. 2012;19:783-787.

75. Havla J, Gerdes LA, Meinl I, et al. De-escalation from natalizumab in multiple sclerosis: recurrence of disease activity despite switching to glatiramer acetate. J Neurol. 2011;258:1665-1669.

76. Borriello G, Prosperini L, Marinelli F, Fubelli F, Pozzilli C. Observations during an elective interruption of natalizumab treatment: a post-marketing study. Mult Scler. 2011;17:372-375.

77. Baumgartner A, Stich O, Rauer S. Clinical and radiological disease reactivation after cessation of long-term therapy with natalizumab. Int J Neurosci. 2012;122:35-39.

78. Sempere AP, Martín-Medina P, Berenguer-Ruiz L, et al. Switching from natalizumab to fingolimod: an observational study. Acta Neurol Scand. January 22, 2013. [Epub ahead of print.]

79. Rinaldi F, Seppi D, Calabrese M, Perini P, Gallo P. Switching therapy from natalizumab to fingolimod in relapsing-remitting multiple sclerosis: clinical and magnetic resonance imaging findings. Mult Scler. 2012;18:1640-1643

80. Daelman L, Maitrot A, Maarouf A, Chaunu MP, Papeix C, Tourbah A. Severe multiple sclerosis reactivation under fingolimod 3 months after natalizumab withdrawal. Mult Scler. 2012;18:1647-1649.

81. Cristiano LM, Bozic C, Bloomgren G. Preliminary evaluationof pregnancy outcomes from the Tysabri (natalizumab) pregnancy exposure registry. Mult Scler. 2011;17:S457.

82. Sørensen PS, Bertolotto A, Edan G, et al. Risk stratification for progressive multifocal leukoencephalopathy in patients treated with natalizumab. Mult Scler. 2012;18:143-152. 
83. Rudick RA. Multiple sclerosis, natalizumab, and PML: helping patients decide. Cleve Clin J Med. 2011;78 Suppl 2:S18-S23.

84. Tur C, Tintorè M, Vidal-Jordana A, et al. Natalizumab discontinuation after PML risk stratification: outcome from a shared and informed decision. Mult Scler. 2012;18:1193-1196.

85. Heesen C, Kleiter I, Nguyen F, et al. Risk perception in natalizumabtreated multiple sclerosis patients and their neurologists. Mult Scler. 2010;16:1507-1512.

86. Thompson JP, Noyes K, Dorsey ER, Schwid SR, Hollowey RG. Quantitative risk-benefit analysis of natalizumab. Neurology. 2008;71:357-364.

87. Duquette P. Deaths and disability from natalizumab are no longer tolerable: yes. Mult Scler. 2012;18:1068-1069.

88. Hutchinson M. Deaths and disability from natalizumab are no longer tolerable: commentary. Mult Scler. 2012;18:1073.

89. Sørensen PS. Deaths and disability from natalizumab are no longer tolerable: no (they can be avoided). Mult Scler. 2012;18:1070-1072.

90. Kappos L, Radue EW, O'Connor P, et al. A placebo-controlled trial of oral fingolimod in relapsing multiple sclerosis. $N$ Engl $J$ Med. 2010;362:387-401.

91. Cohen J, Barkhof F, Comi G, et al. Oral fingolimod or intramuscular interferon for relapsing multiple sclerosis. $N$ Engl J Med. 2010;362: 402-415.

92. Calabresi PA, Goodin D, Jeffery D, et al. Oral fingolimod (FTY720) in relapsing-remitting multiple sclerosis: baseline patient demographics and disease characteristics from a 2-year phase III trial (FREEDOMS II). Neurology. 2010;74(9 Suppl 2):A416-A417.

93. Calabresi PA, Goodin D, Jeffery D, et al. Efficacy and safety of fingolimod versus placebo: primary outcomes from the phase 3 FREEDOMS II study in patients with relapsing-remitting multiple sclerosis. Poster P491 presented at the 28th Congress of the European Committee for Treatment and Research in Multiple Sclerosis, October 10-13, 2012, Lyon, France.

94. Kappos L, Radue EW, O'Connor P, et al. Phase 3 FREEDOMS study extension: fingolimod (FTY720) efficacy in patients with relapsing-remitting multiple sclerosis receiving continuous or placebo-fingolimod switched therapy for up to 4 years. Poster P979 presented at the 28th Congress of the European Committee for Treatment and Research in Multiple Sclerosis, October 10-13, 2012, Lyon, France.

95. O'Connor C, Polman R, Hohlfeld R, et al. Phase III FREEDOMS study extension: long-term safety of fingolimod (FTY720) in relapsing-remitting multiple sclerosis. Poster P523 presented at the 28th Congress of the European Committee for Treatment and Research in Multiple Sclerosis, October 10-13, 2012, Lyon, France.

96. European Medicines Agency. European Medicines Agency gives new advice to better manage risk of adverse effects on the heart with Gilenya. Available from: http://www.ema.europa.eu/docs/ en_GB/docu ment_library/Press_release/2012/04/WC500125690. pdf. Accessed May 11, 2013.

97. Medicines and Healthcare Products Regulatory Agency. Drug Safety Update. Available from: http://www.mhra.gov.uk/home/ groups/dsu/documents/publication/con228756.pdf. Accessed May 11, 2013.

98. European Medicines Agency. European Medicines Agency starts review of Gilenya (fingolimod). Available from: http://www.ema. europa.eu/docs/en_GB/document_library/Press_release/2012/01/ WC500120703.pdf. Accessed May 11, 2013.

99. Jander S, Turowski B, Kieseier BC, Hartung HP. Emerging tumefactive multiple sclerosis after switching therapy from natalizumab to fingolimod. Mult Scler. 2012;18:1650-1652.

100. Hardy TA, Chataway J. Tumefactive demyelination: an approach to diagnosis and management. J Neurol Neurosurg Psychiatry. January 19, 2013. [Epub ahead of print.]

101. Novartis. Available from: http://www.novartis.com/downloads/news room/product-related-info-center/statement-PML.pdf. Accessed January 22, 2013.
102. Gross CM, Baumgartner A, Rauer S, Stich O. Multiple sclerosis rebound following herpes zoster infection and suspension of fingolimod. Neurology. 2012;79:2006-2007.

103. Bourdette D, Gilden D. Fingolimod and multiple sclerosis: four cautionary tales. Neurology. 2012;79:1942-1943.

104. Cohen J. Long-term safety of fingolimod in relapsing multiple sclerosis: update to integrated analyses of phase 2 and 3 studies and extension phases. Poster presented at the 28th Congress of the European Committee for Treatment and Research in Multiple Sclerosis, October 10-13, 2012, Lyon, France.

105. Ontaneda D, Hara-Cleaver C, Rudick RA, Cohen JA, Bermel RA. Early tolerability and safety of fingolimod in clinical practice. J Neurol Sci. 2012;323:167-172.

106. Comi G, Kappos L, Palace J, et al. Cardiac safety of fingolimod $0.5 \mathrm{mg}$ during the first dose observation in 4-month, open-label, multi-center FIRST study in patients with relapsing MS. Abstract S41.003 presented at the 64th American Academy of Neurology Annual Meeting, April 21-28, 2012, New Orleans, LA.

107. Gold R, Comi G, Ziemssen T, et al. Safety of fingolimod in patients with relapsing forms of multiple sclerosis: subgroup analyses from the 4-month, open-label, multicentre FIRST study. Poster P1009 presented at the 28th Congress of the European Committee for Treatment and Research in Multiple Research in Multiple Sclerosis, October 10-13, 2012, Lyon, France.

108. DiMarco JP, O’Connor P, Cohen JA, et al. Fingolimod treatment initiation experience: cardiac and Holter electrocardiogram findings from three phase 3 studies. Poster P530 presented at the 28th Congress of the European Committee for Treatment and Research in Multiple Research in Multiple Sclerosis, October 10-13, 2012, Lyon, France.

109. Ziemssen T, et al. Study design and first interim results of a registry study to establish long-term safety and pharmaco-economic data on fingolimod (Gilenya ${ }^{\circledR}$ ) in multiple sclerosis patients in Germany (PANGAEA). Poster P522 presented at the 28th Congress of the European Committee for Treatment and Research in Multiple Research in Multiple Sclerosis, October 10-13, 2012, Lyon, France.

110. MS-UK. Gilenya. Available from: http://www.ms-uk.org/index.cfm/ gilenya. Accessed May 11, 2013.

111. Papadopoulou A, Kappos L, Sprenger T. Teriflunomide for oral therapy in multiple sclerosis. Expert Rev Clin Pharmacol. 2012;5:617-628.

112. O'Connor PW, Li D, Freedman MS, et al. A Phase II study of the safety and efficacy of teriflunomide in multiple sclerosis with relapses. Neurology. 2006;66:894-900.

113. O'Connor P, Wolinsky JS, Confavreux C, et al. Randomized trial of oral teriflunomide for relapsing multiple sclerosis. $N$ Engl $J$ Med. 2011;365:1293-1303.

114. Kappos L, Comi G, Confavreux C, et al. The efficacy and safety of teriflunomide in patients with relapsing MS: results From TOWER, a Phase 3 placebo-controlled study. Abstract 153 presented at the 28th Congress of the European Committee for Treatment and Research in Multiple Research in Multiple Sclerosis, October 10-13, 2012, Lyon, France.

115. ClinicalTrials.gov. A study comparing the effectiveness and safety of teriflunomide and interferon beta-1a in patients with relapsing multiple sclerosis (TENERE). Available from: http://clinicaltrials.gov/show/ NCT00883337. Accessed May 11, 2013.

116. Confavreux C, Li DK, Freedman MS, et al. Long-term follow-up of a phase 2 study of oral teriflunomide in relapsing multiple sclerosis: safety and efficacy results up to 8.5 years. Mult Scler. 2012;18:1278-1289.

117. Vermersch P. A multicenter, randomized, parallel-group, rater-blinded study comparing the effectiveness and safety of teriflunomide and subcutaneous interferon beta-1a in patients with relapsing multiple sclerosis. Consortium of Multiple Sclerosis Centers-Americas Committee for Treatment and Research in Multiple Sclerosis, 2012.

118. Freedman MS, Wamil B, Cheng S, et al. TERACLES study design: teriflunomide as adjunctive therapy in patients with relapsing multiple sclerosis receiving interferon- $\beta$. Poster presented at the 17th Annual Meeting of the Americas Committee for Treatment and Research in Multiple Sclerosis, June 1-2, 2012, San Diego, CA. 
119. Warnke C, zu Hörste GM, Hartung HP, et al. Review of teriflunomide and its potential in the treatment of multiple sclerosis. Neuropsychiatr Dis Treat. 2009;5:333-340.

120. Available from: http://www.medscape.com/viewarticle/803177. Accessed April 29, 2013.

121. O'Connor P, Bar-Or A, Freedman M, et al. P01 multiple sclerosis: treatment safety. Immune response to seasonal influenza vaccination in patients with relapsing multiple sclerosis treated with teriflunomide: the TERIVA study (P01.169). Neurology. 2013;80:P01.169.

122. He D, Xu Z, Dong S, et al. Teriflunomide for multiple sclerosis. Cochrane Database Syst Rev. 2012;12:CD009882.

123. Roll A, Reich K, Boer A. Use of fumaric acid esters in psoriasis. Indian J Dermatol Venereol Leprol. 2007;73:133-137.

124. Linker RA, Lee DH, Stangel M, Gold R. Fumarates for the treatment of multiple sclerosis: potential mechanisms of action and clinical studies. Exp Rev Neurother. 2008;8:1683-1690.

125. Schimrigk S, Brune N, Hellwig K, et al. Oral fumaric acid esters for the treatment of active multiple sclerosis: an open-label, baseline controlled pilot study. Eur J Neurol. 2006;13:604-610.

126. Linker RA, Lee DH, Ryan S, et al. Fumaric acid esters exert neuroprotective effects in neuroinflammation via activation of the Nrf2 antioxidant pathway. Brain. 2011;134:678-692.

127. Gold R, Kappos L, Arnold DL, et al. Placebo-controlled phase 3 study of oral BG-12 for relapsing multiple sclerosis. $N$ Engl J Med 2012;367:1098-1107.

128. Fox RJ, Miller DH, Phillips JT, et al. Placebo-controlled phase 3 study of oral BG-12 or glatiramer in multiple sclerosis. $N$ Engl J Med. 2012;367:1087-1097.

129. Ropper AH. The "poison chair" treatment for multiple sclerosis. N Engl J Med. 2012;367:1149-1150.

130. Kappos L, Gold R, Miller DH, et al. Efficacy and safety of oral fumarate in patients with relapsing-remitting multiple sclerosis: a multicentre, randomised, double-blind, placebo-controlled phase IIb study. Lancet. 2008;372:1463-1472.

131. Kita M, Fox RJ, Phillips JT, et al. Effects of BG-12 (dimethyl fumarate) on quality of life in patients with relapsing-remitting multiple sclerosis: findings from the CONFIRM Study. Poster P586 presented at the 28th Congress of the European Committee for Treatment and Research in Multiple Sclerosis, October 10-13, 2012, Lyon, France.

132. Hoefnagel JJ, Thio HB, Willemze R, Bouwes-Bavinck JN. Long-term safety aspects of systemic therapy with fumaric acid esters in severe psoriasis. Br J Dermatol. 2003;149:363-369.

133. van Oosten BW, Killestein J, Barkhof F, Polman CH, Wattjes MP. PML in a patient treated with dimethyl fumarate from a compounding pharmacy. N Engl J Med. 2013;368:1658-1659.

134. Ermis U, Weis J, Schulz JB. PML in a patient treated with fumaric acid. $N$ Engl J Med. 2013;368:1657-1658.

135. Sweetser TM, Dawson KT, Bozic C. Manufacturer's response to case reports of PML. N Engl J Med. 2013;368:1659-1661.

136. Friedrich M, Sterry W, Klein A, Rückert R, Döcke WD, Asadullah K. Addition of pentoxifylline could reduce the side effects of fumaric acid esters in the treatment of psoriasis. Acta Derm Venereol. 2001;81: 429-451.

137. ClinicalTrials.gov. A study in healthy volunteers to evaluate effects of pre-medication or slow dose titration on flushing and gastrointestinal events. Available from: http://clinicaltrials.gov/ct2/show/ NCT01568112. Accessed May 10, 2013.

138. Limmroth V. Oral BG12 for treatment of relapsing-remitting MS. Nat Rev Neurol. 2013;9:8-10.

139. Phillips JT, Fox RJ, Selmaj K, et al. Long-term safety and tolerability of oral BG-12 (dimethyl fumarate) in relapsing-remitting multiple sclerosis: interim results from ENDORSE. Poster P1103 presented at the 28th Congress of the European Committee for Treatment and Research in Multiple Sclerosis, October 10-13, 2012, Lyon, France.

140. Kieseier BC, Jeffery DR. Chemotherapeutics in the treatment of multiple sclerosis. Ther Adv Neurol Disord. 2010;3:277-291.
141. Casetta I, Iuliano G, Filippini G. Azathioprine for multiple sclerosis. Cochrane Database Syst Rev. 2007;4:CD003982.

142. Massacesi L, Parigi A, Barilaro A, et al. Efficacy of azathioprine on multiple sclerosis new brain lesions evaluated using magnetic resonance imaging. Arch Neurol. 2005;62:1843-1847.

143. Adverse Drug Reactions Advisory Committee. Drug-induced pancreatitis. Aust Adv Drug React Bull. 2006;25:22.

144. Dubinsky MC, Yang H, Hassard PV, et al. 6-MP metabolite profiles provide a biochemical explanation for 6-MP resistance in patients with inflammatory bowel disease. Gastroenterology. 2002;122:904-915.

145. Confavreux C, Saddier P, Grimaud J, Moreau T, Adeleine P, Aimard G. Risk of cancer from azathioprine therapy in multiple sclerosis: a case-control study. Neurology. 1996;46:1607-1612.

146. Silman AJ, Petrie J, Hazleman B, Evans SJ. Lymphoproliferative cancer and other malignancies in patients with rheumatoid arthritis treated with azathioprine: a 20 year follow up study. Ann Rheum Dis. 1988;47:988-992.

147. Patti F, Lo Fermo S. Lights and shadows of cyclophosphamide in the treatment of multiple sclerosis. Autoimmune Dis. 2011;2011:961702.

148. Awad A, Stüve O. Cyclophosphamide in multiple sclerosis: scientific rationale, history and novel treatment paradigms. Ther Adv Neurol Disord. 2009;2:50-61.

149. Rinaldi L, Perini P, Calabrese M, Gallo P. Cyclophosphamide as second-line therapy in multiple sclerosis: benefits and risks. Neurol Sci. 2009;30 Suppl 2:171-173.

150. Radis CD, Kahl LE, Baker GL, et al. Effects of cyclophosphamide on the development of malignancy and on long-term survival of patients with rheumatoid arthritis: a 20-year follow up study. Arthritis Rheum. 1995;38:1120-1127.

151. Talar-Williams C, Hijazi YM, Walther MM, et al. Cyclophosphamideinduced cystitis and bladder cancer in patients with Wegener granulomatosis. Ann Intern Med. 1996;124:477-484.

152. Patti F, Reggio E, Palermo F, et al. Stabilization of rapidly worsening multiple sclerosis for 36 months in patients treated with interferon beta plus cyclophosphamide followed by interferon beta. J Neurol. 2004;251:1502-1506.

153. Smith DR, Weinstock-Guttman B, Cohen JA, et al. A randomized blinded trial of combination therapy with cyclophosphamide in patients-with active multiple sclerosis on interferon beta. Mult Scler. 2005;11:573-582.

154. Hu X, Miller L, Richman S, et al. A novel PEGylated interferon beta-1a for multiple sclerosis: safety, pharmacology, and biology. J Clin Pharmacol. 2012;52:798-808.

155. Calabresi P, Kieseier B, Arnold D, et al. ADVANCE phase 3 study of PEGylated interferon beta-1a for relapsing multiple sclerosis: patient baseline characteristics. Neurology. 2012;78:P01.133.

156. López V, Molina I, Monteagudo C, Jordá E. Cutaneous sarcoidosis developing after treatment with pegylated interferon and ribavirin: a new case and review of the literature. Int J Dermatol. 2011;503 287-291.

157. Giacomini PS, Bar-Or A. Laquinimod in multiple sclerosis. Clin Immunol. 2012;142:38-43.

158. Polman C, Barkhof F, Sandberg-Wollheim M, Linde A, Nordle $\mathrm{O}$, Nederman T. Treatment with laquinimod reduces development of active MRI lesions in relapsing MS. Neurology. 2005;64: 987-991.

159. Comi G, Pulizzi A, Rovaris M, et al. Effect of laquinimod on MRImonitored disease activity in patients with relapsing-remitting multiple sclerosis: a multicentre, randomised, double-blind, placebo-controlled phase IIb study. Lancet. 2008;371:2085-2092.

160. Comi G, Abramsky O, Arbizu T, et al. LAQ/5063 Study Group. Oral laquinimod in patients with relapsing-remitting multiple sclerosis: 36-week double-blind active extension of the multi-centre, randomized, double-blind, parallel-group placebo-controlled study. Mult Scler. 2010;16:1360-1366.

161. Comi G, Jeffery D, Kappos L, et al. Placebo-controlled trial of oral laquinimod for multiple sclerosis. $N$ Engl J Med. 2012;366:1000-1009. 
162. Clinical Trials.gov. BRAVO study: laquinimod double blind placebo controlled study in RRMS patients with a rater blinded reference arm of interferon $\beta$-1a $\left(\right.$ Avonex $\left.^{\circledR}\right)$. Available from: http://www.clinicaltri als.gov/ct2/show/NCT00605215. Accessed April 29, 2013.

163. Clinical Trials.gov. The efficacy and safety and tolerability of laquinimod in subjects with relapsing remitting multiple sclerosis (RRMS) (CONCERTO). Available from: http://clinicaltrials.gov/show/ NCT01707992. Accessed April 29, 2013.

164. Coles AJ, Compston DA, Selmaj KW, et al. Alemtuzumab vs interferon beta-1a in early multiple sclerosis. $N$ Engl J Med. 2008;359: 1786-1801.

165. Cohen JA, Coles AJ, Arnold DL, et al. Alemtuzumab versus interferon beta 1a as first-line treatment for patients with relapsing-remitting multiple sclerosis: a randomised controlled phase 3 trial. Lancet. 2012;380:1819-1828.

166. Coles AJ, Twyman CL, Arnold DL, et al. Alemtuzumab for patients with relapsing multiple sclerosis after disease-modifying therapy: a randomised controlled phase 3 trial. Lancet. 2012;380:1829-1839.

167. Coles AJ. Alemtuzumab therapy for multiple sclerosis. Neurotherapeutics. 2013;10:29-33.

168. Coles AJ, Fox E, Vladic A, et al. Alemtuzumab more effective than interferon $\beta$-1a at 5-year follow-up of CAMMS223 clinical trial. Neurology. 2012;78:1069-1078.

169. Fontoura P. Monoclonal antibody therapy in multiple sclerosis: paradigm shifts and emerging challenges. MAbs. 2010;2:670-681.

170. Lulu S, Waubant E. Humoral-targeted immunotherapies in multiple sclerosis. Neurotherapeutics. 2013;10:34-43.

171. Bielekova B. Daclizumab therapy for multiple sclerosis. Neurotherapeutics. 2013;10:55-67.

172. Liu J, Wang L, Zhan SY, Xia Y. Daclizumab for relapsing remitting multiple sclerosis. Cochrane Database Syst Rev. 2012;4:CD008127.

173. Stüve $O$, Greenberg BM. Anticipated benefits and surprising effects of daclizumab in multiple sclerosis. Lancet Neurol. 2010;9:337-338.

174. Wynn D, Kaufman M, Montalban X, et al. Daclizumab in active relapsing multiple sclerosis (CHOICE study): a phase 2, randomised, double-blind, placebo-controlled, add-on trial with interferon beta. Lancet Neurol. 2010;9:381-390.

175. Gold R, Giovannoni G, Selmaj K, et al. Daclizumab high-yield process in relapsing-remitting multiple sclerosis (SELECT): a randomised, double-blind, placebo-controlled trial. Lancet. April 3, 2013. [Epub ahead of print.]

176. Clinical Trials.gov. Efficacy and safety of daclizumab high yield process versus interferon $\beta$ 1a in patients with relapsing-remitting multiple sclerosis (DECIDE). Available from: http://clinicaltrials.gov/ ct2/show/NCT01064401. Accessed May 11, 2013.

177. Cross AH, Klein RS, Piccio L. Rituximab combination therapy in relapsing multiple sclerosis. Ther Adv Neurol Disord. 2012;5:311-319.

178. Jacob A, Weinshenker BG, Violich I, et al. Treatment of neuromyelitis optica with rituximab. Retrospective analysis of 25 patients. Arch Neurol. 2008;65:1443-1448.

179. Hauser SL, Waubant E, Arnold DL, et al. B-cell depletion with rituximab in relapsing-remitting multiple sclerosis. $N$ Engl $J$ Med. 2008;358:676-688.

180. Hawker K, O'Connor P, Freedman MS, et al. Rituximab in patients with primary progressive multiple sclerosis: results of a randomized double blind placebo-controlled multicenter trial. Ann Neurol. 2009;66:460-471.

181. Carson KR, Evens AM, Richey EA, et al. Progressive multifocal leukoencephalopathy after rituximab therapy in HIV-negative patients: a report of 57 cases from the Research on Adverse Drug Events and Reports project. Blood. 2009;113:4834-4840.

182. Molloy ES, Calabrese LH. Progressive multifocal leukoencephalopathy associated with immunosuppressive therapy in rheumatic diseases: evolving role of biologic therapies. Arthritis Rheum. 2012;64: 3043-3051

183. He D, Zhou H, Han W, Zhang S. Rituximab for relapsing-remitting multiple sclerosis. Cochrane Database Syst Rev. 2011;12:CD009130.
184. Kappos L, Li D, Calabresi PA, et al. Ocrelizumab in relapsing-remitting multiple sclerosis: a phase 2, randomised, placebo-controlled, multicentre trial. Lancet. 2011;378(9805):1779-1787.

185. Hutas G. Ocrelizumab, a humanized monoclonal antibody against CD20 for inflammatory disorders and B-cell malignancies. Curr Opin Investig Drugs. 2008;9:1206-1215.

186. ThePharmaLetter. Roche/Biogen drop development of ocrelizumab in rheumatoid arthritis. Available from: http://www.thepharmaletter. com/file/95109/rochebiogen-drop-development-of-ocrelizumab-inrheumatoid-arthritis.html. Accessed May 11, 2013.

187. Emery P, Rigby W, Tak PP, et al. Serious infections with ocrelizumab in rheumatoid arthritis: pooled results from double-blind periods of the ocrelizumab phase III RA program. Poster 414 presented at the American College of Rheumatology/Association of Rheumatology Health Professionals 74th Annual Scientific Meeting, November 6-11, 2010, Atlanta, GA.

188. Chaudhuri A. Ocrelizumab in multiple sclerosis: risks and benefits. Lancet. 2012:379:1196-1197.

189. Gold R. Combination therapies in multiple sclerosis. J Neurol. 2008;255 Suppl 1:51-60.

190. Smith DR, Weinstock-Guttman B, Cohen JA, et al. A randomized blinded trial of combination therapy with cyclophosphamide in patients-with active multiple sclerosis on interferon beta. Mult Scler. 2005;11:573-582.

191. Perini P, Calabrese M, Rinaldi L, Gallo P. Cyclophosphamide-based combination therapies for autoimmunity. Neurol Sci. 2008;29 Supp1 2: S233-S234.

192. Reggio E, Nicoletti A, Fiorilla T, Politi G, Reggio A, Patti F. The combination of cyclophosphamide plus interferon beta as rescue therapy could be used to treat relapsing-remitting multiple sclerosis patients - twenty-four months follow-up. J Neurol. 2005;252: $1255-1261$.

193. Cohen JA, Imrey PB, Calabresi PA, et al. Results of the Avonex Combination Trial (ACT) in relapsing-remitting MS. Neurology. 2009;72:535-541.

194. Edan G, Comi G, Le Page E, et al. Mitoxantrone prior to interferon beta-1b in aggressive relapsing multiple sclerosis: a 3-year randomised trial. J Neurol Neurosurg Psychiatry. 2011;82:1344-1350.

195. Rieckmann P, Heidenreich F, Sailer M, et al. Treatment de-escalation after mitoxantrone therapy: results of a phase IV, multicentre, open-label, randomized study of subcutaneous interferon beta1a in patients with relapsing multiple sclerosis. Ther Adv Neurol Disord. 2012;5:3-12.

196. Bhardwaj S, Coleman CI, Sobieraj DM. Efficacy of statins in combination with interferon therapy in multiple sclerosis: a meta-analysis. Am J Health Syst Pharm. 2012;69:1494-1499.

197. Shaygannejad V, Janghorbani M, Ashtari F, Dehghan H. Effects of adjunct low-dose vitamin $\mathrm{d}$ on relapsing-remitting multiple sclerosis progression: preliminary findings of a randomized placebo-controlled trial. Mult Scler Int. 2012;2012:452541.

198. Soilu-Hänninen M, Aivo J, Lindström BM, et al. A randomised, double blind, placebo controlled trial with vitamin D3 as an add on treatment to interferon $\beta-1 \mathrm{~b}$ in patients with multiple sclerosis. J Neurol Neurosurg Psychiatry. 2012;83:565-571.

199. Pozzilli C, De Giglio L, Barletta V, et al. Efficacy and safety of oral contraceptives as add-on therapy in patients with relapsing-remitting multiple sclerosis receiving subcutaneous interferon beta-1a: a multicenter, randomized investigator-run clinical trial. Poster P171 presented at the 28th Congress of the European Committee for Treatment and Research in Multiple Sclerosis, October 10-13, 2012, Lyon, France.

200. Cross AH, Klein RS, Piccio L. Rituximab combination therapy in relapsing multiple sclerosis. Ther Adv Neurol Disord. 2012;5: 311-319.

201. Solari A, Acquarone N, Pucci E, et al. Communicating the diagnosis of multiple sclerosis - a qualitative study. Mult Scler. 2007;13: 763-769. 
202. Kasper J, Heesen C, Köpke S, Fulcher G, Geiger F. Patients' and observers' perceptions of involvement differ. Validation study on inter-relating measures for shared decision making. PLoS One. 2011;6:e26255.

203. Simioni S, Schluep M, Bault N, et al. Multiple sclerosis decreases explicit counterfactual processing and risk taking in decision making. PLoS One. 2012;7:e50718.

204. Kachuck NJ. When neurologist and patient disagree on reasonable risk: new challenges in prescribing for patients with multiple sclerosis Neuropsychiatr Dis Treat. 2011;7:197-208.

205. Girouard N, Soucy N. Patient considerations in the management of multiple sclerosis: development and clinical utility of oral agents. Patient Prefer Adherence. 2011;5:101-108.

206. Giordano A, Mattarozzi K, Pucci E, et al. Participation in medical decision-making: attitudes of Italians with multiple sclerosis. J Neurol Sci. 2008;275:86-91.

207. Lejbkowicz I, Caspi O, Miller A. Participatory medicine and patient empowerment towards personalized healthcare in multiple sclerosis Expert Rev Neurother. 2012;12:343-352.

208. Solari A, Martinelli V, Trojano M, et al. An information aid for newly diagnosed multiple sclerosis patients improves disease knowledge and satisfaction with care. Mult Scler. 2010;16:1393-1405.

209. Johnson FR, Van Houtven G, Ozdemir S, et al. Multiple sclerosis patients' benefit-risk preferences: serious adverse event risks versus treatment efficacy. J Neurol. 2009;256:554-562.

210. Jeffery DR. Recent advances in treating multiple sclerosis: efficacy, risks and place in therapy. Ther Adv Chronic Dis. 2013;4:45-51.

211. Sheridan C. Safety profiles come to fore as more drugs approach MS market. Nat Biotechnol. 2012;30:6-8.

212. Gasperini C, Ruggieri S, Development of oral agent in the treatment of multiple sclerosis: how the first available oral therapy, fingolimod will change therapeutic paradigm approach. Drug Des Devel Ther. 2012;6:175-186.

213. Smith B, Carson S, Fu R, et al. Drug class review: disease-modifying drugs for multiple sclerosis: Final Update 1 Report. Portland, OR: Oregon Health and Science University; 2010. Available from: http:// www.ncbi.nlm.nih.gov/books/NBK50570/. Accessed May 11, 2013.

214. Roach ES. Early multiple sclerosis: to treat or not to treat? Arch Neurol. 2006;63:619

215. Woo DA, Olek MJ, Frohman EM. Diagnosis and management of multiple sclerosis: case studies. Neurol Clin. 2006;24:199-214.

216. Boster A, Edan G, Frohman E, et al. Intense immunosuppression in patients with rapidly worsening multiple sclerosis: treatment guidelines for the clinician. Lancet Neurol. 2008;7:173-183.

217. Pittock SJ, Weinshenker BG, Noseworthy JH, et al. Not every patient with multiple sclerosis should be treated at time of diagnosis. Arch Neurol. 2006;63:611-614.

218. Tintoré M. New options for early treatment of multiple sclerosis. J Neurol Sci. 2009;277 Suppl 1:S9-S11.

219. Bunyan RF, Tang J, Weinshenker B. Acute demyelinating disorders: emergencies and management. Neurol Clin. 2012;30:285-307.

220. Freedman MS. Do not treat from CIS onset: evaluate disease course and prognosis first-no (treat!). Mult Scler. 2012;18:394-395.

221. Hutchinson M. Truly benign multiple sclerosis is rare: let's stop fooling ourselves - commentary. Mult Scler. 2012;18:15.

222. Bergamaschi R. Can we predict the evolution of an unpredictable disease like multiple sclerosis? Eur J Neurol. October 31, 2012. [Epub ahead of print.]

223. Frohman EM, Racke M, van Den Noort S. To treat, or not to treat: the therapeutic dilemma of idiopathic monosymptomatic demyelinating syndromes. Arch Neurol. 2000;57:930-932.

224. Frohman EM, Havrdova E, Lublin F, et al. Most patients with multiple sclerosis or a clinically isolated demyelinating syndrome should be treated at the time of diagnosis. Arch Neurol. 2006;63:614-619.

225. Freedman MS, Patry DG, Grand'Maison F, Myles ML, Paty DW, Selchen DH. Treatment optimization in multiple sclerosis. Can $J$ Neurol Sci. 2004;31:157-168.
226. Goodin DS, Biermann LD, Bohlega S, et al. Integrating an evidencebased assessment of benefit and risk in disease-modifying treatment of multiple sclerosis. Curr Med Res Opin. 2007;23:2823-2832.

227. Wiendl H, Toyka KV, Rieckmann P, Gold R, Hartung HP, Hohlfeld R. Basic and escalating immunomodulatory treatments in multiple sclerosis: current therapeutic recommendations. J Neurol. 2008;255:1449-1463.

228. Freedman MS, Forrestal FG. Canadian treatment optimization recommendations (TOR) as a predictor of disease breakthrough in patients with multiple sclerosis treated with interferon beta-1a: analysis of the PRISMS study. Mult Scler. 2008;14:1234-1241.

229. Coyle PK. Switching algorithms: from one immunomodulatory agent to another. J Neurol. 2008;255 Suppl 1:44-50.

230. Castillo-Trivino T, Mowry EM, Gajofatto A, et al. Switching multiple sclerosis patients with breakthrough disease to second-line therapy. PLoS One. 2011;6:e16664

231. Prosperini L, Borriello G, De Giglio L, Leonardi L, Barletta V, Pozzilli C. Management of breakthrough disease in patients with multiple sclerosis: when an increasing of interferon beta dose should be effective? BMC Neurol. 2011;11:26.

232. Gajofatto A, Bacchetti P, Grimes B, High A, Waubant E. Switching first-line disease-modifying therapy after failure: impact on the course of relapsing-remitting multiple sclerosis. Mult Scler. 2009;15: $50-58$.

233. Río J, Tintoré M, Sastre-Garriga J, et al. Change in the clinical activity of multiple sclerosis after treatment switch for suboptimal response. Eur J Neurol. 2012;19:899-904.

234. Sormani M, Rio J, Tintorè M, et al. Scoring treatment response in patients with relapsing multiple sclerosis. Mult Scler. 2013;19:605-612.

235. Keyhanian K, Davoudi V, Etemadifar M, Amin M. Better prognosis of multiple sclerosis in patients who experienced a full-term pregnancy. Eur Neurol. 2012;68:150-155.

236. Houtchens MK, Kolb CM. Multiple sclerosis and pregnancy: therapeutic considerations. $J$ Neurol. August 25, 2012. [Epub ahead of print.]

237. Michel L, Foucher Y, Vukusic S, et al. Increased risk of multiple sclerosis relapse after in vitro fertilisation. J Neurol Neurosurg Psychiatry. 2012;83:796-802.

238. Giannini M, Portaccio E, Ghezzi A, et al. Pregnancy and fetal outcomes after Glatiramer Acetate exposure in patients with multiple sclerosis: a prospective observational multicentric study. BMC Neurol. 2012;12:124

239. Portaccio E, Ghezzi A, Hakiki B, et al. Breastfeeding is not related to postpartum relapses in multiple sclerosis. Neurology. 2011;77:145-150.

240. Hellwig K, Haghikia A, Rockhoff M, Gold R. Multiple sclerosis and pregnancy: experience from a nationwide database in Germany. Ther Adv Neurol Disord. 2012;5:247-253.

241. De Las Heras V, De Andrés C, Téllez N, Tintoré M. Pregnancy in multiple sclerosis patients treated with immunomodulators prior to or during part of the pregnancy: a descriptive study in the Spanish population. Mult Scler. 2007;13:981-984.

242. Fragoso YD, Boggildb M, Macias-Islasc MA, et al. The effects of long-term exposure to disease-modifying drugs during pregnancy in multiple sclerosis. Clin Neurol Neurosurg. 2013;115:154-159.

243. Alwan S, Sadovnick AD. Multiple sclerosis and pregnancy: maternal considerations. Womens Health (Lond Engl). 2012;8:399-414.

244. Lu E, Wang BW, Guimond C, Synnes A, Sadovnick D, Tremlett H. Disease-modifying drugs for multiple sclerosis in pregnancy: a systematic review. Neurology. 2012;79:1130-1135.

245. Bigi S, Banwell B. Pediatric multiple sclerosis. J Child Neurol. 2012;27:1378-1383.

246. Chitnis T. Disease-modifying therapy of pediatric multiple sclerosis. Neurotherapeutics. 2013;10:89-96.

247. Arnal-Garcia C, García-Montero MR, Málaga I, et al. Natalizumab use in pediatric patients with relapsing-remitting multiple sclerosis Eur J Paediatr Neurol. 2013;17:50-54.

248. Ghezzi A. Therapeutic strategies in childhood multiple sclerosis. Ther Adv Neurol Disord. 2010;3:217-228. 
249. Ghezzi A, Pozzilli C, Grimaldi LM, et al. Safety and efficacy of natalizumab in children with multiple sclerosis. Neurology. 2010;75:912-917.

250. Ghezzi A, Pozzilli C, Grimaldi L, et al. Natalizumab in pediatric multiple sclerosis: results of a cohort of 55 cases. Mult Scler. February 11, 2013. [Epub ahead of print.]

251. Tenembaum SN. Ethical challenges in paediatric clinical trials in multiple sclerosis. Ther Adv Neurol Disord. 2012;5:139-146.

252. Chitnis T, Tenembaum S, Banwell B, et al. Consensus statement: evaluation of new and existing therapeutics for pediatric multiple sclerosis. Mult Scler. 2012;18:116-127.
253. Paparrigopoulos T, Ferentinos P, Kouzoupis A, Koutsis G, Papadimitriou GN. The neuropsychiatry of multiple sclerosis: focus on disorders of mood, affect and behaviour. Int Rev Psychiatry. 2010;22: 14-21.

254. Siegert RJ, Abernethy DA. Depression in multiple sclerosis: a review. J Neurol Neurosurg Psychiatry. 2005;76:469-475.

255. Pucak ML, Carroll KA, Kerr DA, Kaplin AI. Neuropsychiatric manifestations of depression in multiple sclerosis: neuroinflammatory, neuroendocrine, and neurotrophic mechanisms in the pathogenesis of immune-mediated depression. Dialogues Clin Neurosci. 2007;9: $125-139$.

\section{Publish your work in this journal}

Neuropsychiatric Disease and Treatment is an international, peerreviewed journal of clinical therapeutics and pharmacology focusing on concise rapid reporting of clinical or pre-clinical studies on a range of neuropsychiatric and neurological disorders. This journal is indexed on PubMed Central, the 'PsycINFO' database and CAS.
The manuscript management system is completely online and includes a very quick and fair peer-review system, which is all easy to use. Visit http://www.dovepress.com/testimonials.php to read real quotes from published authors.

Submit your manuscript here: http://www.dovepress.com/neuropsychiatric-disease-and-treatment-journal 